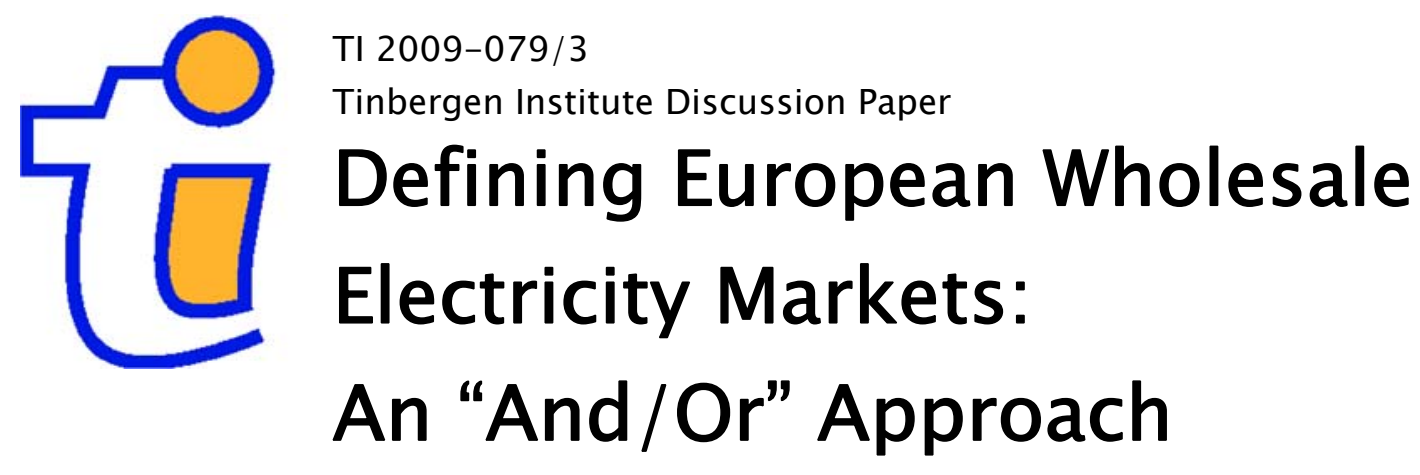

Elbert Dijkgraaf',2

Maarten C.W. Janssen ${ }^{1,3}$

' Erasmus School of Economics, Erasmus University Rotterdam, Tinbergen Institute, 2 SEOR,

3 University of Vienna. 


\section{Tinbergen Institute}

The Tinbergen Institute is the institute for economic research of the Erasmus Universiteit Rotterdam, Universiteit van Amsterdam, and Vrije Universiteit Amsterdam.

Tinbergen Institute Amsterdam

Roetersstraat 31

1018 WB Amsterdam

The Netherlands

Tel.: +31(0)205513500

Fax: $+31(0) 205513555$

Tinbergen Institute Rotterdam

Burg. Oudlaan 50

3062 PA Rotterdam

The Netherlands

Tel.: + $31(0) 104088900$

Fax: $+31(0) 104089031$

Most TI discussion papers can be downloaded at http://www.tinbergen.nl. 


\title{
Defining European Wholesale Electricity Markets: An “And/or" Approach
}

\author{
Elbert Dijkgraaf Erasmus School of Economics and SEOR, Erasmus University Rotterdam, H 7-25, P.O. Box 1738, 3000 DR \\ Rotterdam, The Netherlands, Tel: 3110 4082590, Fax: 3110 4089650, Email: dijkgraaf@ese.eur.nl, corresponding author
}

\author{
Maarten C.W. Janssen University of Vienna and Erasmus University Rotterdam, Hohenstaufengasse 9, 1010 Wien, Austria, \\ Email: maarten.janssen@univie.ac.at
}

September 2009

\begin{abstract}
An important question in the dynamic European wholesale markets for electricity is whether to define the geographical market at the level of an individual member state or more broadly. We show that if we currently take the traditional approach by considering for each member state whether there is one single other country that provides a substitute for domestic production, the market in each separate member state has still to be considered a separate market. However, if we allow for the possibility that at different moments in time there is another country that provides a substitute for domestic production, then the conclusion should be that certain member states do not constitute a separate geographical market. This is in particular true for Belgium, but also for The Netherlands, France, and to some extent also for Germany and Austria. We call this alternative approach the "and/or" approach.
\end{abstract}

Key words: Electricity, convergence, market definition, market coupling JEL codes: L94, L40

Correspondence: Elbert Dijkgraaf, Erasmus School of Economics and SEOR, Erasmus University Rotterdam, H 7-25, P.O. Box 1738, 3000 DR Rotterdam, The Netherlands, Tel: 31 10 4082590, Fax: 3110 4089650, Email: dijkgraaf@ese.eur.nl 


\section{Introduction}

Electricity markets in Europe are undergoing important changes, mainly because of the attempt of the European Commission to create one, large European market that is liberalized and free of excessive regulation. An important step in the process of creating one European market is the construction of much larger interconnection capacities to trade electricity across borders of different member states. ${ }^{1}$ In reaction to these policy developments, the industry is in a process of restructuring and relatively many mergers and acquisitions are taken place. National competition authorities and regulators are faced with the question how to evaluate these activities. A first, important step in these evaluations is to assess the relevant product market. At a retail level, it seems by and large clear that the relevant market is not larger than the national level. At the wholesale level, however, this is less clear. In this paper we address the question how to define wholesale electricity markets in Europe. As explained above, this question is relevant to assess how successful the general policy of the European Commission is and also for evaluating an actual merger or acquisition proposal.

Relevant markets are typically defined by answering the question whether two individual products are substitutes for each other (EU, 1997). If a competition authority concludes that no single product acts as a full substitute, then the product under consideration is considered to constitute its own relevant market and the HHI (or some alternative measure in the case of electricity markets, such as the Pivotal Supplier Index (PSI) or the Residual Supplier Index (RSI)) calculated in that market is considered to be a proper indication of whether that market is concentrated and a firm's market share in that market a proper indication of whether a firm has a dominant position. Electricity itself is, of course, a homogeneous good so that the question concerning the definition of the relevant market is mainly a question concerning the definition of the geographical market (and thus implicitly whether import capacity is such that electricity produced in neighboring countries can act as a substitute for domestically produced electricity in satisfying local demand).

Due to the arbitrage possibilities, electricity prices in the different countries should be identical if import capacity is abundant so that there is one geographical market. Even more, since November 21, 2006 the power exchanges of the Netherlands, Belgium and France are linked and the interconnection capacity is optimally used in the bidding process so that

\footnotetext{
${ }^{1}$ In the past, the production (and distribution) of electricity in each individual European country was in the hands of (local) government-owned agencies. The capacity to import and export electricity was also rather limited.
} 
arbitrage possibilities between wholesale electricity prices in these three countries are automatically exploited if existing. Electricity prices can only be different across different neighboring countries if import capacity forms a bottleneck.

Due to the fact that electricity cannot be stored, there is also a time dimension in defining the market: the electricity market between 8 and 9 am, for example, is different from the market between 9 and $10 \mathrm{pm}$. Import capacity may be large enough in non-peak hours to be able to speak about one non-peak market that is larger than an individual country, but if the interconnection capacity is still too small in peak hours to be able to provide domestic users an alternative supply, then the conclusion may be that one should stick to a narrowly defined market (certainly for peak hours). This is especially the case as large firms may benefit greatly from a dominant position during peak hours. The fact that overall the different national electricity wholesale prices seem to be close to each other may not be enough reason for competition authorities to conclude that there is one (large) relevant market as market power (if existing) can imply very high profits in a relatively small time period.

In this paper we want to argue that the approach to defining the relevant geographical market by considering for each member state (and each hour) whether there is one single other country that provides a substitute for domestic production has important limitations. In particular, such an approach does not take into account the high volatility of demand and the technical limitations of the transmission network. Due to the non-storability of electric energy the size of the relevant market in the electricity sector (and the market by which it is constrained) changes from hour-to-hour. We show that if we currently take the traditional approach, the market in each separate member state has still to be considered a separate market. However, if we allow for the possibility that at a certain hour there is either one country or another country (or both or more) that provides a substitute for domestic production, then the conclusion should be that certain member states do not constitute a separate geographical market. This is in particular true for Belgium, but also for The Netherlands, France, and to some extent for Germany and Austria. In fact, one may argue that these countries are close to forming one large wholesale electricity market. In contrast, even if we use this "and/or" approach for countries like Italy, Spain and the Nordic countries, united in Nordpool, ${ }^{2}$ the conclusion should be that they remain separate geographic markets.

\footnotetext{
${ }^{2}$ These countries include Sweden, Norway, Denmark and Finland.
} 
It is clear that a firm producing electricity in country A is more constrained in its behavior by electricity producers in countries B and/or C than by producers in countries B only or C only. How large the "and/or" effect is depends on the size of the different cross border interconnection capacities in relation to the size and form (nuclear, gas, coal) of domestic electricity demand and supply. We show that in comparison to other countries Belgium has a relatively large cross border interconnection capacity implying that the "and/or" effect in Belgium should be larger than in neighboring countries. The analysis shows that the effect for Belgium is so large that at any point in time, there is always at least one other country (most notably France and/or The Netherlands) that forms a competitive constraint on the Belgian wholesale market, even though the French and Dutch electricity production by itself cannot be considered a full substitute for electricity produced in Belgium as there are hours during the day where import capacity forms a bottleneck for an integrated market. This, of course, does not mean that we may never expect to observe high prices in the Belgian wholesale market. However, when the Belgian wholesale prices are high the corresponding prices in France and/or The Netherlands are also high.

The definition of the relevant electricity market has important repercussion for how to consider firm conduct or possible (horizontal or vertical) mergers. If an individual country is the relevant product market, a firm that is mainly operating in the wholesale market of that country is much more likely to have a dominant position it could potentially exploit. On the other hand, if the geographical market is wider, the behavior of that company is constrained by foreign electricity producers.

As far as we know, this is the first article analyzing the issue of market definition by taking the possibility of a competitive constraint imposed by multiple alternative products (countries) into account. This "and/or" approach we argue fits well the "flighty" nature of electricity markets. There exists, of course, some literature taking a more traditional approach toward market definition analyzing the process of price convergence in wholesale European electricity markets. ${ }^{3}$ For instance, using hourly data up to 2004 Zachmann (2005) finds clear convergence between Germany and the Netherlands for 12 out of 24 hours. However, there was no full convergence at the end of this period, since significant price differentials for peak

\footnotetext{
${ }^{3}$ Many papers analyze the price level itself as electricity has some characteristics that result in a different pricing behavior compared with other products (e.g. Knittel and Roberts, 2005 and Mount et al. 2006). As long as electricity producers belong to the same market this literature does not interfere with our study. However, it might explain why prices in countries differ at some points of time.
} 
hours were still present. Armstrong and Galli (2005) find that also for peak hours the differential decreased between 2002 and 2004. They used hourly data for Germany, France, the Netherlands and Spain. Bosco et al (2006) find strong, but not perfect, integration of the German, French, Austrian and Dutch market using weekly median data for the period March 2002 till June 2006. Dijkgraaf and Janssen (2007) explore price convergence further as new hourly data are available for 2007. Their paper shows that the process of price convergence has continued since 2005 also for peak hours and that it is likely that in some years from now there will be a fully integrated European wholesale electricity market. Robinson (2007) uses yearly data as this makes it possible to study convergence from a longer historical perspective. He concludes that a process towards convergence is present using yearly data for nine EUcountries from 1978 till 2003. Pelagatti et al. (2007) uses weekly media data for the period January 1999 till March 2007. They compare electricity prices for Austria, France, Germany, the Netherlands, Spain and the Nordic countries. They analyze whether countries share a common trend and do find this for Austria, France, Germany and the Netherlands. Zachman (2008) uses hourly data for Austria, the Czech Republic, Denmark, France, Germany, the Netherlands, Poland, Spain, Sweden and the UK) from 2002 to mid 2006. He tests whether pairs of countries show convergence and concludes that this is increasingly the case, but that for a significant share of observations no full convergence is present. Perrot-Voisard and Zachmann (2009), also take the flighty nature of electricity markets as a starting-point. They propose an alternative concentration measure that takes into account how often prices in two countries differ more than $5 \%$ from each other.

The rest of the paper is organized as follows. In Section 2 we describe the methodology employed, the data used and some descriptive statistics. Section 3 gives the results and Section 4 concludes.

\section{Methodology, data and descriptive statistics}

As explained in the introduction, electricity prices vary by the hour as electricity is a nonstorable product. Daily per hour wholesale prices for the one-day-ahead market in Belgium, France, Germany, The Netherlands, the Nordic countries (Finland, Sweden, Norway, Denmark), Poland and Spain over the period of 22 November 2006 until 21 December 2008 (two years, 731 observations for each hour in all countries) are publicly available. ${ }^{45}$ The

\footnotetext{
${ }^{4}$ See www.apx.nl, www.eex.com, www.belpex.be, www.powernext.fr, www.nordpool.com. www.polpx.pl, www.omel.es, www.mercatoelelettrico.org.
} 
starting date is chosen to be one day after 21 November 2006 as this is the date that the Belgian power exchange started and the power exchanges of the Netherlands, Belgium and France were coupled. These prices are taken from the respective national electricity power exchanges BELPEX, PWXT, EEX, APX, EXAA, IPEX, NordPool, POLPX and Omel. To get some idea about these data, Figure 1 gives a picture of how average electricity prices per hour over the observation period vary over the 24 hours of a day. ${ }^{6}$ Figures $2 \mathrm{a}$ and $2 \mathrm{~b}$ provide two time series of how hourly electricity prices have varied over the time horizon.

\section{Figure 1. Average price in $€ / M W h$ per hour}

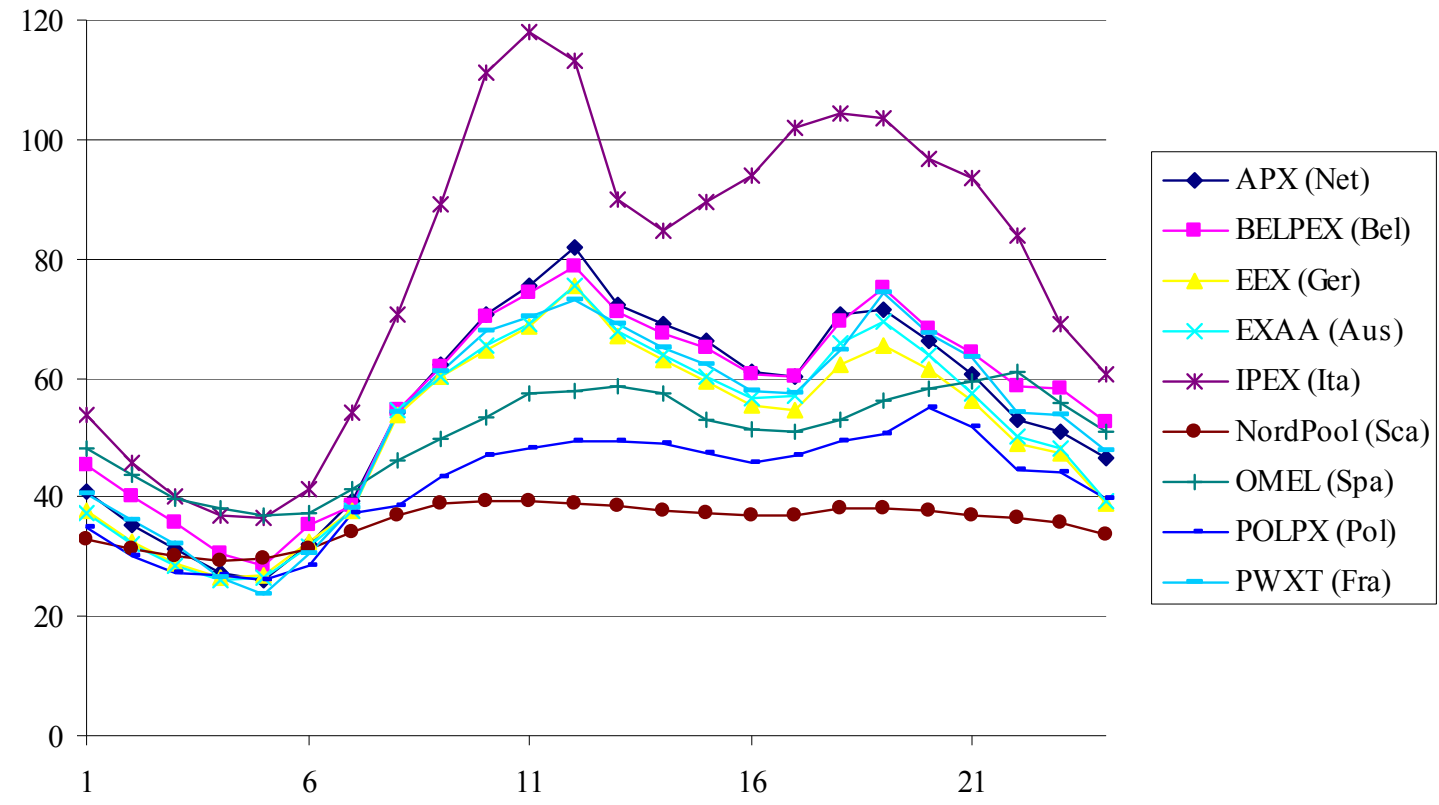

These descriptive statistics make two things very clear. First, from Figure 1 it is clear that in most countries there is a difference between peak hours and non-peak hours, with peak hours being defined as the $9^{\text {th }}$ till the $20^{\text {th }}$ hour. ${ }^{7}$ Prices in peak hours are around $€ 50 / \mathrm{MWh}$ and higher. Prices in non-peak hours are typically around $€ 45 / \mathrm{MWh}$ and lower. The only marked exception to this pattern are the Nordic countries where average prices are roughly stable over the day, possibly because of the relatively extensive use of water power. Prices in the peak period itself have two marked peaks, around noon and around the $19^{\text {th }}$ hour. This difference

\footnotetext{
${ }^{5}$ Observations are excluded if prices are less than 0.05 euro per MWh as this indicates that at that hour there was (nearly) no demand for electricity. Data are also excluded for Belgium for two days due to exceptional circumstances (availability problems): 26/1/2008 (hours 1-6 and 22-24) and 3/5/2008.

${ }^{6}$ See Appendix A for the most important descriptive statistics.

${ }^{7}$ Of course, one can argue where the exact boundary between peak and non-peak hours is. This is not to deny, however, that there is a marked difference between the two periods.
} 
plays also some role in the details of the interpretation of our results in the next Section. Moreover, we can already see from Figure 1 that the electricity prices in Austria, Belgium, France, Germany and The Netherlands are somewhat grouped together and distinct from the lower prices in the Nordic countries, Spain and Poland and the markedly higher prices in Italy. Second, in Figures $2 \mathrm{a}$ and 2b, we have depicted a typical time series of one peak and one non-peak hour as a function of time. From the Figures it is clear that there is much more variation in the peak hour series than in the non-peak hour series. ${ }^{8}$ Moreover, the two pictures convey the idea that the time series we are dealing with are stationary. If we want to be justified in simply regressing hourly wholesale electricity prices in one country on (composite) hourly wholesale electricity prices of (a set of) other countries using OLS, then we should exclude the possibility of the time series being non-stationary.

\section{Figure 2a. Price hour 6 in $€ / M W h$ at BELPEX per day}

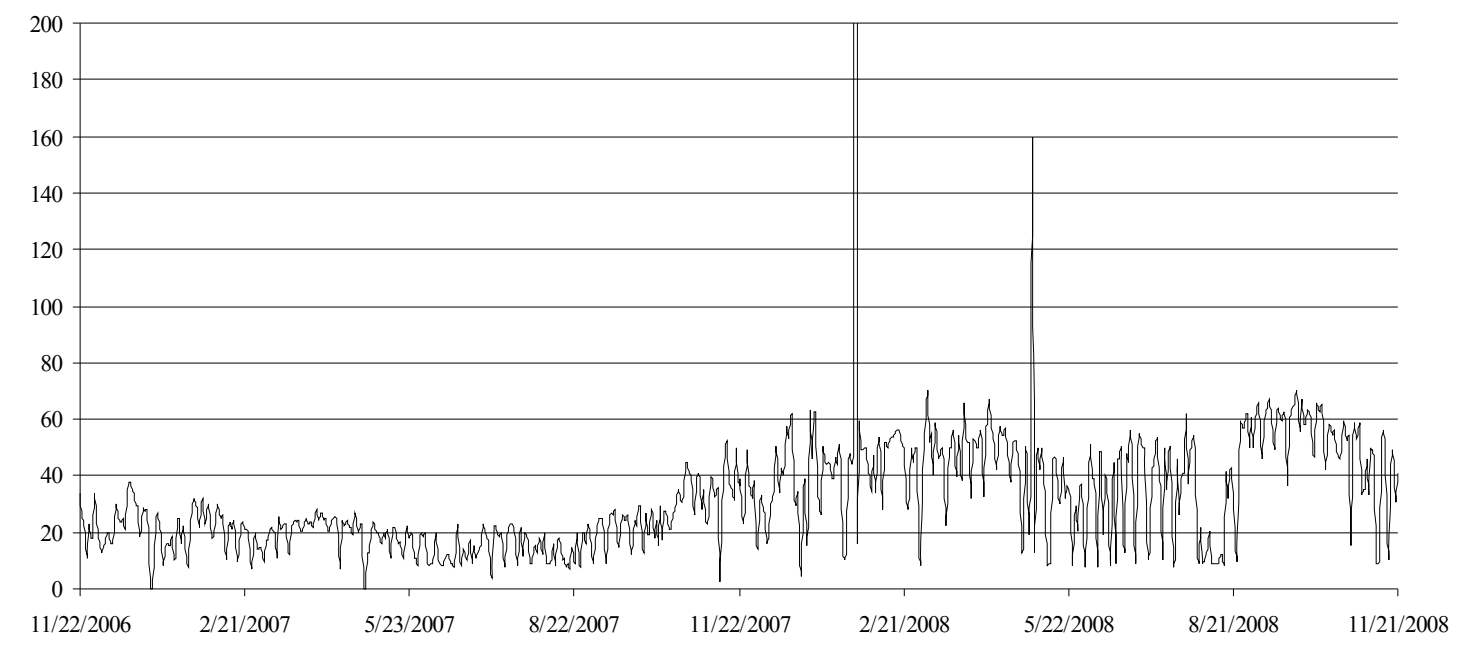

We formally test for stationarity using $y_{t}=\phi+\gamma y_{t-1}+\varepsilon_{t}$, where $y_{t}$ is the price of wholesale electricity in a certain country and a certain hour at day $t$ and $\gamma$ and $\varphi$ are parameters to be estimated, and show, using an augmented Dickey-Fuller test (see, e.g., Greene, 2000), that we can reject the hypothesis that there is a unit root nearly in all cases. ${ }^{9}$ Accordingly, we

\footnotetext{
${ }^{8}$ To make the figures comparable, the horizontal axis has a maximal value of 200 euro per MW. For the $18^{\text {th }}$ hour some days show a higher price than this maximum. Note that price spikes are a regular phenomenon in electricity markets (Huisman and Mahieu, 2003).

${ }^{9}$ Only for Nordpool (hour 1505 and 20 to 24) and POLPX (hours 2 and 3) we cannot reject the unit root hypothesis. We therefore also analyze whether our conclusions are robust for estimations in first differences.
} 
subsequently perform the standard approach in the literature (e.g. Armstrong and Galli, 2005 and Zachman, 2005) and do a simple regression analysis of the form

$$
P_{h, t}^{j}=\alpha+\beta P_{h, t}^{i \neq j}+\varepsilon
$$

where $P_{h, t}^{j}$ are the price of wholesale electricity in country $j$ at a certain hour $h$ at day $t$ and $\alpha$ and $\beta$ are parameters to be estimated. ${ }^{10}$ If the two countries have one fully integrated market, one should expect in equation (1) to find that $\alpha=0$ and $\beta=1$. Apart from the coefficients, the $R^{2}$ is also a very relevant indicator of how tight electricity prices in two countries are connected to each other. Even if the coefficients are close to what is expected it may be that the $\mathrm{R}^{2}$ is still not very high, indicating that there are days in which the prices in the two countries show a significant difference. Only when $\alpha=0, \beta=1$ and the $\mathrm{R}^{2}$ is close to 1 , can we speak of an integrated market where the price in one country imposes a competitive constraint on the price of another country at (almost) every moment.

\section{Figure 2b. Price hour 18 in $€ / M W h$ at BELPEX per day}

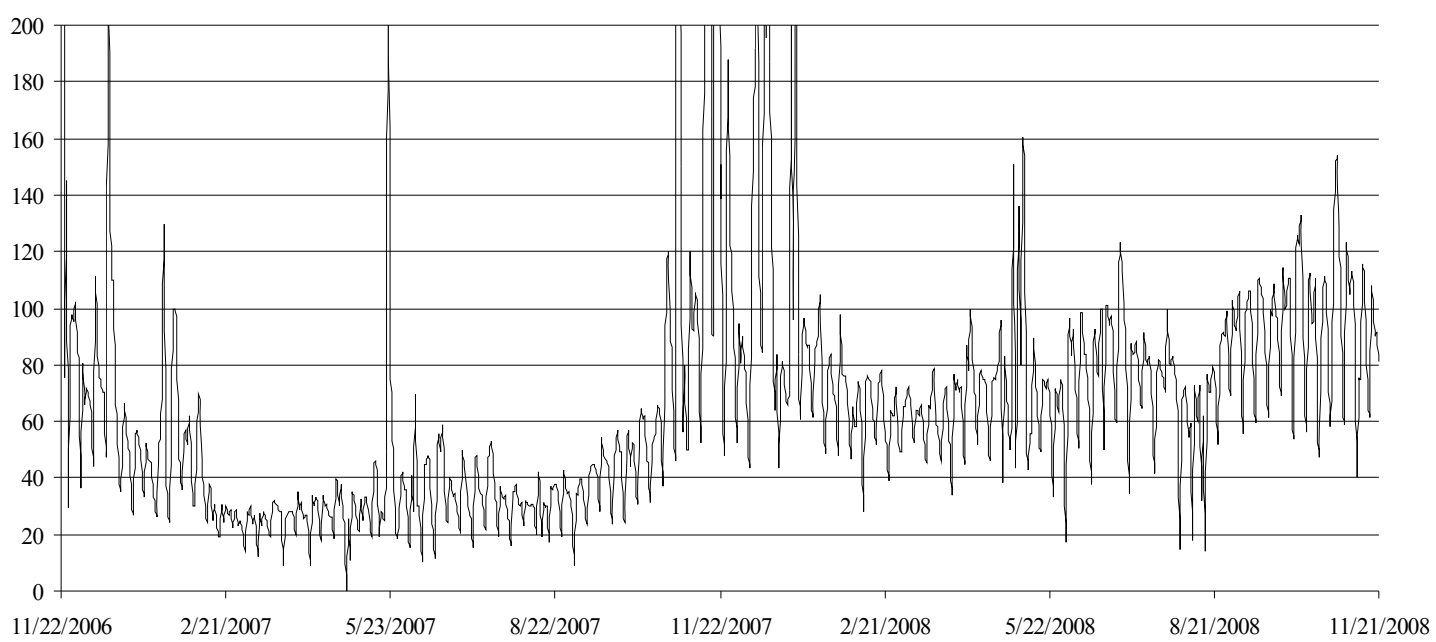

To test the idea that a competitive constraint is imposed by a combination of countries, but not by one country on its own, we perform a similar analysis but we replace the price of one other country as "explanatory" variable, by a composite variable (MIX), where for each day we take that observation from the set of observations for all other countries that is closest to the price observation of the country that needs to be explained. In the analysis presented here we have not restricted the composite variable to the neighboring countries of the country under

\footnotetext{
${ }^{10}$ Including a trend in the estimations does not change our conclusions.
} 
consideration. This is because, in principle, one could buy electricity in the wholesale market in any other country and buy the necessary interconnection capacity at an auction. This is, of course, more complicated for countries that are relatively far apart from each other, but not impossible both in theory and in practice. ${ }^{11}$ This is particularly so for France and the Netherlands where the market connection that has been established in November 2006 makes importing and exporting between these two countries a lot easier.

Table 1a. Observations (\%) with less than $1 \%$ price difference: all hours

\begin{tabular}{rrrrrrrrrr}
\hline & APX & BELPEX & EEX & EXAA & IPEX & NordPool & OMEL & POLPX & PWXT \\
\hline APX & - & 78 & 6 & 9 & 2 & 1 & 4 & 2 & 67 \\
BELPEX & 78 & - & 6 & 8 & 2 & 1 & 4 & 2 & 87 \\
EEX & 6 & 6 & - & 7 & 1 & 2 & 3 & 2 & 6 \\
EXAA & 9 & 8 & 7 & - & 1 & 2 & 2 & 2 & 8 \\
IPEX & 2 & 2 & 1 & 1 & - & 0 & 1 & 1 & 2 \\
NordPool & 1 & 1 & 2 & 2 & 0 & - & 1 & 1 & 1 \\
OMEL & 4 & 4 & 3 & 2 & 1 & 1 & - & 3 & 4 \\
POLPX & 2 & 2 & 2 & 2 & 1 & 1 & 2 & - & 2 \\
PWXT & 67 & 87 & 6 & 8 & 2 & 1 & 4 & 2 & - \\
MIX & 82 & 98 & 21 & 23 & 6 & 8 & 11 & 11 & 90 \\
\hline
\end{tabular}

Table 1b. Observations (\%) with less than $10 \%$ price difference: all hours

\begin{tabular}{rrrrrrrrrr}
\hline & APX & BELPEX & EEX & EXAA & IPEX & NordPool & OMEL & POLPX & PWXT \\
\hline APX & - & 85 & 49 & 60 & 17 & 14 & 28 & 21 & 78 \\
BELPEX & 85 & - & 46 & 54 & 18 & 14 & 28 & 20 & 91 \\
EEX & 50 & 47 & - & 55 & 13 & 16 & 24 & 24 & 48 \\
EXAA & 61 & 55 & 55 & - & 14 & 16 & 24 & 24 & 54 \\
IPEX & 16 & 17 & 13 & 14 & - & 4 & 12 & 6 & 17 \\
NordPool & 14 & 14 & 17 & 16 & 4 & - & 14 & 17 & 14 \\
OMEL & 28 & 28 & 24 & 24 & 12 & 14 & - & 28 & 29 \\
POLPX & 22 & 21 & 24 & 24 & 6 & 16 & 25 & - & 21 \\
PWXT & 78 & 91 & 47 & 54 & 17 & 14 & 29 & 20 & - \\
MIX & 97 & 99 & 84 & 88 & 36 & 45 & 59 & 64 & 98 \\
\hline
\end{tabular}

Of course, one already can get some idea whether prices are significantly similar to each other by simply looking what percentage of the day's electricity prices in two countries differ less than $1 \%$ or $10 \%$ from each other or from the composite prices. These descriptive statistics for

\footnotetext{
${ }^{11}$ As a robustness check, we have performed a similar analysis, but restricting the composite variable to the neighboring countries. This is of course, somewhat problematic also becauise we do not have data for neighboring countries that are not in the data set (this is of particular importance for Poland and Austria). The results of this analysis qualitatively support the conclusions we report here. Details can be obtained from the authors (or can be checked independently as all data sources are publicly available).
} 
all countries are presented in Table 1 a for a $1 \%$ difference and in Table $1 \mathrm{~b}$ for a $10 \%$ difference.

Table 1a clearly shows that Belgian wholesale electricity prices differ almost always less than $1 \%$ from either the Dutch or the French electricity prices. Comparing the Belgian wholesale electricity prices with the composite price of Dutch, French and German prices (MIX) shows that the fit is almost perfect, in $98 \%$ of the observations is the difference less than $1 \%$. This is not nearly so perfect the case for other countries, although also for the Dutch (APX) and French (PWXT) markets the percentage is quite high. When one takes the allowable difference to be $10 \%$ also the EEX (Germany), EXAA (Austria) show a good fit with the MIX data. The potential power of the "and/or" approach can especially be seen when considering the table $1 \mathrm{~b}$ for EEX and EXAA. There is no individual country that has on more than 55\% $(60 \%)$ of the observations a difference of less than $10 \%$ with the prices quoted at the respective power exchange, however when one makes a composite index to compare the data with, there is a close resemblance in $84(88) \%$ of the observations.

Table 2a. Interconnection capacity between two countries in the data set

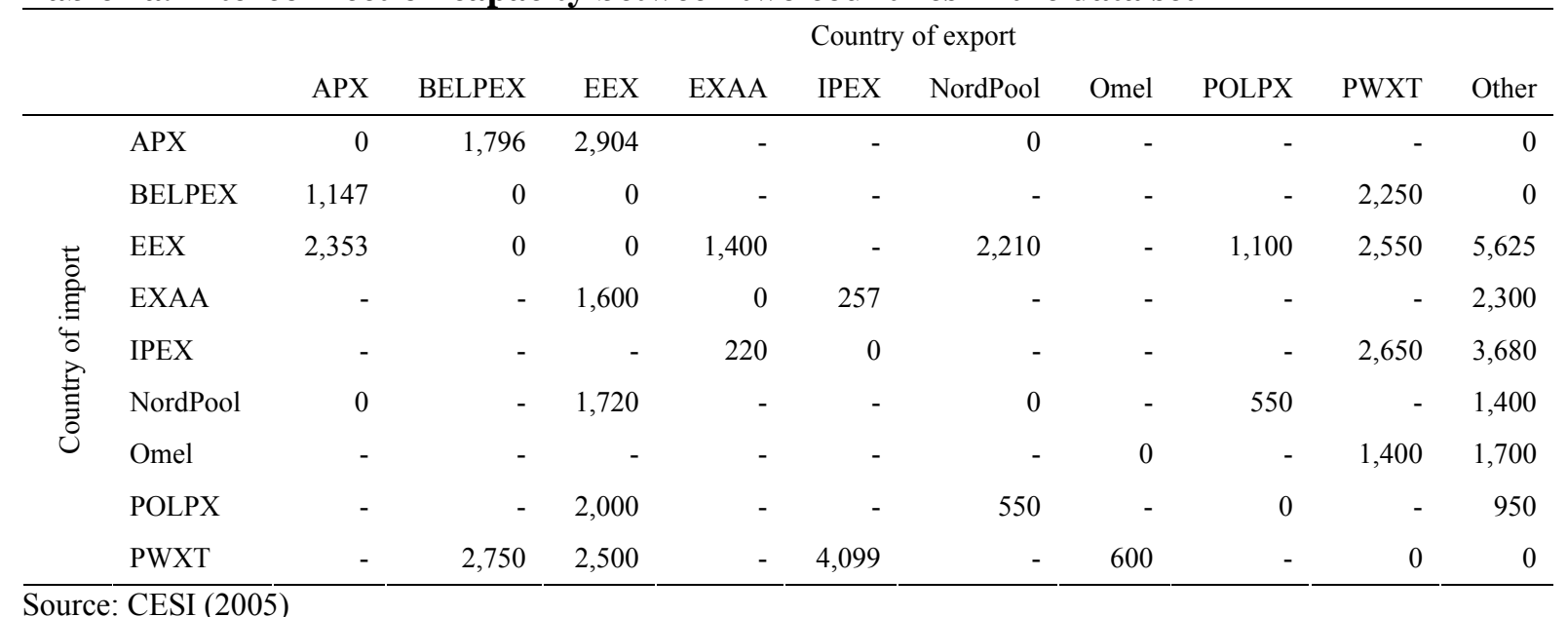

One explanation for this almost perfect fit between the Belgian electricity prices and the composite price of electricity prices is that the interconnection capacity, expressed as a percentage of the total nationwide available production capacity is indeed the highest in Belgium as described in Table $2 b .^{12}$ The same is true, but to a lesser extent, for The Netherlands, Germany, Austria and France. Table 2a gives the basic information about interconnection capacity between two countries. One can also see from both tables that for

\footnotetext{
${ }^{12}$ One should be careful, however, with such a conclusion as interconnection capacity may be congested. Pelagatti et al. (2007, p. 6 ) write that this is frequently the case for Germany.
} 
Poland (the country with the largest import capacity as a percentage of domestic production after these countries) most of the capacity comes from Germany and as German wholesale electricity prices are typically higher than the Polish prices, Germany does not impose much of a competitive constraint on Poland.

Table 2b. Import capacity (as a percentage of installed production)

\begin{tabular}{lrrrrr}
\hline & \multicolumn{2}{c}{ Total import capacity (MW) } & $\begin{array}{r}\text { Installed } \\
\text { capacity (MW) }\end{array}$ & \multicolumn{2}{c}{ Share import capacity (\% of capacity) } \\
& $\begin{array}{r}\text { Excluding } \\
\text { countries outside } \\
\text { the data set }\end{array}$ & $\begin{array}{r}\text { Including } \\
\text { countries outside } \\
\text { the data set }\end{array}$ & & $\begin{array}{r}\text { Excluding } \\
\text { Country level }\end{array}$ & $\begin{array}{r}\text { Including } \\
\text { the data set }\end{array}$ \\
\hline APX & 4,700 & 4,700 & 20,926 & 22 & 22 \\
BELPEX & 3,397 & 3,397 & 14,305 & 24 & 24 \\
EEX & 9,613 & 15,238 & 120,859 & 8 & 13 \\
EXAA & 1,857 & 4,157 & 14,664 & 13 & 28 \\
IPEX & 2,870 & 6,550 & 71,171 & 4 & 9 \\
NordPool & 2,270 & 3,670 & 74,075 & 3 & 5 \\
Omel & 1,400 & 3,100 & 66,388 & 2 & 5 \\
POLPX & 2,550 & 3,500 & 30,019 & 8 & 12 \\
PWXT & 9,949 & 9,949 & 103,900 & 10 & 10 \\
\hline
\end{tabular}

Source: CESI (2005)

\section{Results}

In this section we provide four sets of results. The first set of results concerns the preliminary test on the stationarity of the time series involved. As for most of the time series we can clearly reject the hypothesis that the time series are non-stationary, we subsequently simply perform OLS analyses of the relation (expressed in equation (1)) between wholesale electricity prices at individual power exchanges and corresponding prices in neighboring countries and then also between prices at individual power exchanges and corresponding composite prices. In these analyses, we take Belgium as a showcase as the results for that country in general, and the impact of our new approach in particular, are the starkest. The focus on one individual country also serves a didactical purpose of showing the details of the analysis. We also show the corresponding results for all countries in general overview tables. Finally, we do a robustness check by presenting the results of the analysis in first differences. 


\subsection{Testing for non-stationarity (unit roots)}

As described in the former section we test for stationarity using the augmented Dickey-Fuller test. Table 3 presents the result for the hypothesis of a unit root in the electricity prices. This hypothesis is rejected for nearly all 24 hours. Only for NordPool (hour 1 to 5 and 20 to 24) and POLPX (hour 2 and 3) the test rejects a unit root. As already said, at the end of this Section we also analyze whether our conclusions are robust for estimations in first differences as a sensitivity analyses.

\subsection{Individual country comparisons}

We next present the results of the analysis where a country's wholesale price is explained in terms of the prices in one other country. We first focus on Belgian wholesale electricity prices and ask how these prices compare with similar prices in surrounding countries. In table 4 we present, we focus on the relation with France (as this is the strongest link) and in table 5 we also present the global results for all individual country comparisons. For every hour of the data, the analysis is based on estimating the coefficients of equation (1). Table 4 presents the estimation results for estimating equation (1) for every hour separately with French PWXT prices as explanatory variables and Belgian prices as the variable to be explained and we use a Wald-test to test the hypothesis that the coefficients are equal to 0 and 1 , respectively.

It becomes clear from reading the table that in almost all peak hours (except for hours 15, 16, 17 and 20) we reject the hypothesis that the coefficients are indeed equal to 0 and 1 (what needs to be the case when markets are fully integrated). Although the coefficient for PWXT is always close to 1 , the constant is often positive and significant implying a higher price level in

Belgium compared to France. However, even when the hypothesis is not rejected the $\mathrm{R}^{2}$ is not very close to 1 indicating that there is no perfect match between the prices in the two countries.

Moreover, we have also estimated the average price difference and it turns out that this average price difference can be larger in peak hours where the test result is positive than in non-peak hours where the test result shows that the two series are not identical. Economic significance (in terms of whether or not firms can gain significant profits because of price margins) is thus not identical to statistical significance. For instance, Table 4 shows that the average price difference in hour 1 is $€ 0.18$ per $\mathrm{MWh}$ and a statistical test result indicating that the two series are not identical, whereas the average price difference in hour 17 is $€ 2.83$ 
Table 3. Unit root tests

\begin{tabular}{|c|c|c|c|c|c|c|c|c|c|c|c|c|c|c|c|c|c|c|}
\hline \multirow[b]{2}{*}{ Hour } & \multicolumn{2}{|c|}{ APX } & \multicolumn{2}{|c|}{ BELPEX } & \multicolumn{2}{|c|}{ EEX } & \multicolumn{2}{|c|}{ EXAA } & \multicolumn{2}{|c|}{ IPEX } & \multicolumn{2}{|c|}{ NordPool } & \multicolumn{2}{|c|}{ Omel } & \multicolumn{2}{|c|}{ POLPX } & \multicolumn{2}{|c|}{ PWXT } \\
\hline & Test & Prob & Test & Prob & Test & Prob & Test & Prob & Test & Prob & Test & Prob & Test & Prob & Test & Prob & Test & Prob \\
\hline 1 & -6.0 & 0.00 & -5.2 & 0.00 & -6.3 & 0.00 & -5.0 & 0.00 & -6.8 & 0.00 & -1.7 & 0.44 & -5.4 & 0.00 & -3.8 & 0.00 & -5.5 & 0.00 \\
\hline 2 & -5.7 & 0.00 & -5.9 & 0.00 & -7.3 & 0.00 & -6.1 & 0.00 & -7.6 & 0.00 & -2.0 & 0.30 & -4.8 & 0.00 & -2.3 & 0.17 & -6.1 & 0.00 \\
\hline 3 & -6.1 & 0.00 & -6.2 & 0.00 & -7.6 & 0.00 & -6.9 & 0.00 & -8.2 & 0.00 & -2.3 & 0.18 & -4.6 & 0.00 & -2.5 & 0.11 & -6.7 & 0.00 \\
\hline 4 & -7.0 & 0.00 & -7.3 & 0.00 & -8.0 & 0.00 & -7.0 & 0.00 & -9.2 & 0.00 & -2.5 & 0.11 & -4.4 & 0.00 & -3.5 & 0.01 & -7.4 & 0.00 \\
\hline 5 & -7.1 & 0.00 & -7.2 & 0.00 & -7.1 & 0.00 & -7.3 & 0.00 & -8.8 & 0.00 & -2.7 & 0.07 & -4.3 & 0.00 & -4.0 & 0.00 & -7.5 & 0.00 \\
\hline 6 & -8.5 & 0.00 & -8.0 & 0.00 & -8.8 & 0.00 & -9.1 & 0.00 & -8.4 & 0.00 & -3.4 & 0.01 & -3.4 & 0.01 & -5.2 & 0.00 & -8.1 & 0.00 \\
\hline 7 & -10.3 & 0.00 & -9.8 & 0.00 & -9.9 & 0.00 & -11.1 & 0.00 & -10.4 & 0.00 & -4.8 & 0.00 & -3.2 & 0.02 & -4.9 & 0.00 & -9.5 & 0.00 \\
\hline 8 & -11.1 & 0.00 & -10.9 & 0.00 & -11.9 & 0.00 & -12.0 & 0.00 & -11.4 & 0.00 & -6.0 & 0.00 & -5.7 & 0.00 & -5.2 & 0.00 & -10.4 & 0.00 \\
\hline 9 & -11.2 & 0.00 & -10.8 & 0.00 & -11.6 & 0.00 & -11.2 & 0.00 & -12.9 & 0.00 & -6.2 & 0.00 & -7.5 & 0.00 & -5.3 & 0.00 & -10.2 & 0.00 \\
\hline 10 & -11.6 & 0.00 & -11.7 & 0.00 & -10.3 & 0.00 & -10.4 & 0.00 & -16.3 & 0.00 & -5.2 & 0.00 & -6.7 & 0.00 & -5.0 & 0.00 & -10.6 & 0.00 \\
\hline 11 & -13.2 & 0.00 & -12.9 & 0.00 & -10.0 & 0.00 & -10.1 & 0.00 & -15.0 & 0.00 & -4.5 & 0.00 & -5.8 & 0.00 & -4.6 & 0.00 & -10.6 & 0.00 \\
\hline 12 & -13.4 & 0.00 & -12.6 & 0.00 & -11.1 & 0.00 & -10.7 & 0.00 & -13.7 & 0.00 & -4.0 & 0.00 & -5.5 & 0.00 & -4.5 & 0.00 & -9.7 & 0.00 \\
\hline 13 & -10.2 & 0.00 & -9.4 & 0.00 & -9.2 & 0.00 & -9.7 & 0.00 & -9.2 & 0.00 & -3.9 & 0.00 & -5.4 & 0.00 & -4.5 & 0.00 & -8.4 & 0.00 \\
\hline 14 & -11.9 & 0.00 & -10.8 & 0.00 & -10.4 & 0.00 & -10.2 & 0.00 & -10.3 & 0.00 & -4.1 & 0.00 & -4.9 & 0.00 & -4.6 & 0.00 & -8.6 & 0.00 \\
\hline 15 & -13.7 & 0.00 & -13.0 & 0.00 & -10.7 & 0.00 & -10.6 & 0.00 & -12.6 & 0.00 & -4.2 & 0.00 & -4.4 & 0.00 & -5.3 & 0.00 & -8.9 & 0.00 \\
\hline 16 & -14.1 & 0.00 & -13.5 & 0.00 & -10.4 & 0.00 & -10.6 & 0.00 & -14.6 & 0.00 & -3.8 & 0.00 & -5.3 & 0.00 & -5.9 & 0.00 & -9.5 & 0.00 \\
\hline 17 & -14.3 & 0.00 & -14.2 & 0.00 & -9.8 & 0.00 & -10.6 & 0.00 & -14.8 & 0.00 & -3.6 & 0.01 & -5.9 & 0.00 & -8.4 & 0.00 & -10.9 & 0.00 \\
\hline 18 & -15.4 & 0.00 & -15.3 & 0.00 & -10.5 & 0.00 & -10.8 & 0.00 & -10.7 & 0.00 & -4.0 & 0.00 & -6.2 & 0.00 & -11.2 & 0.00 & -11.5 & 0.00 \\
\hline 19 & -9.8 & 0.00 & -13.6 & 0.00 & -10.1 & 0.00 & -10.5 & 0.00 & -8.0 & 0.00 & -3.3 & 0.01 & -5.0 & 0.00 & -11.6 & 0.00 & -13.6 & 0.00 \\
\hline 20 & -6.8 & 0.00 & -11.5 & 0.00 & -7.2 & 0.00 & -7.6 & 0.00 & -6.8 & 0.00 & -2.7 & 0.07 & -3.7 & 0.00 & -9.2 & 0.00 & -11.4 & 0.00 \\
\hline 21 & -5.0 & 0.00 & -16.7 & 0.00 & -6.4 & 0.00 & -6.1 & 0.00 & -7.8 & 0.00 & -2.6 & 0.09 & -3.3 & 0.02 & -8.1 & 0.00 & -16.7 & 0.00 \\
\hline 22 & -4.1 & 0.00 & -6.1 & 0.00 & -5.3 & 0.00 & -4.9 & 0.00 & -6.9 & 0.00 & -2.6 & 0.10 & -4.1 & 0.00 & -7.3 & 0.00 & -5.9 & 0.00 \\
\hline 23 & -3.8 & 0.00 & -4.2 & 0.00 & -4.0 & 0.00 & -3.6 & 0.01 & -5.2 & 0.00 & -2.2 & 0.20 & -4.4 & 0.00 & -6.1 & 0.00 & -4.2 & 0.00 \\
\hline 24 & -4.2 & 0.00 & -4.7 & 0.00 & -4.2 & 0.00 & -3.8 & 0.00 & -4.9 & 0.00 & -1.8 & 0.40 & -4.8 & 0.00 & -4.5 & 0.00 & -4.7 & 0.00 \\
\hline
\end{tabular}

Notes: Bold test statistics are not significant at 5\%. Probability based on MacKinnon (1996) one-sided test. Tested hypothesis is presence of unit root. 
Table 4. Estimation results BELPEX as function of PWXT

\begin{tabular}{|c|c|c|c|c|c|c|c|c|c|c|}
\hline & \multicolumn{2}{|c|}{ PWXT } & \multicolumn{2}{|c|}{ Constant } & \multicolumn{3}{|c|}{ Wald-test $^{1}$} & \multicolumn{2}{|c|}{ Difference } & \multirow[b]{2}{*}{ Conclusion } \\
\hline & Coeff & St. error & Coeff & St. error & $\mathrm{R}^{2}$ & Wald & Prob. & Effect $^{2}$ & $\%$ mean & \\
\hline 1 & 0.98 & 0.01 & 1.18 & 0.30 & 0.97 & 7.49 & 0.00 & 0.18 & 0.45 & Rejected \\
\hline 2 & 0.97 & 0.01 & 0.55 & 0.27 & 0.97 & 12.27 & 0.00 & -0.37 & -1.01 & Rejected \\
\hline 3 & 0.95 & 0.01 & 1.16 & 0.35 & 0.93 & 14.47 & 0.00 & -0.35 & -1.10 & Rejected \\
\hline 4 & 0.96 & 0.01 & 1.28 & 0.34 & 0.91 & 7.70 & 0.00 & 0.12 & 0.44 & Rejected \\
\hline 5 & 0.98 & 0.01 & 1.12 & 0.32 & 0.91 & 8.80 & 0.00 & 0.61 & 2.56 & Rejected \\
\hline 6 & 0.97 & 0.01 & 1.17 & 0.36 & 0.92 & 5.17 & 0.01 & 0.27 & 0.88 & Rejected \\
\hline 7 & 0.98 & 0.01 & 1.13 & 0.40 & 0.94 & 3.92 & 0.02 & 0.30 & 0.79 & Rejected \\
\hline 8 & 0.98 & 0.01 & 1.63 & 0.49 & 0.95 & 5.49 & 0.00 & 0.35 & 0.66 & Rejected \\
\hline 9 & 0.98 & 0.01 & 1.86 & 0.58 & 0.95 & 6.02 & 0.00 & 0.75 & 1.23 & Rejected \\
\hline 10 & 0.99 & 0.02 & 3.32 & 1.45 & 0.80 & 5.61 & 0.00 & 2.41 & 3.56 & Rejected \\
\hline 11 & 0.98 & 0.03 & 4.98 & 2.41 & 0.60 & 4.31 & 0.01 & 3.51 & 4.98 & Rejected \\
\hline 12 & 0.99 & 0.03 & 6.14 & 2.93 & 0.52 & 6.85 & 0.00 & 5.25 & 7.18 & Rejected \\
\hline 13 & 0.99 & 0.02 & 2.47 & 1.16 & 0.85 & 6.83 & 0.00 & 1.79 & 2.59 & Rejected \\
\hline 14 & 0.99 & 0.02 & 3.03 & 1.75 & 0.69 & 5.83 & 0.00 & 2.50 & 3.85 & Rejected \\
\hline 15 & 0.99 & 0.04 & 3.28 & 2.89 & 0.44 & 2.33 & 0.10 & 2.71 & 4.36 & $\mathrm{OK}$ \\
\hline 16 & 0.99 & 0.04 & 2.84 & 2.82 & 0.42 & 1.88 & 0.15 & 2.42 & 4.17 & $\mathrm{OK}$ \\
\hline 17 & 0.99 & 0.04 & 3.69 & 2.55 & 0.47 & 2.51 & 0.08 & 2.83 & 4.93 & $\mathrm{OK}$ \\
\hline 18 & 0.99 & 0.03 & 4.96 & 2.16 & 0.67 & 5.78 & 0.00 & 4.63 & 7.17 & Rejected \\
\hline 19 & 1.00 & 0.00 & 1.11 & 0.29 & 1.00 & 8.48 & 0.00 & 0.85 & 1.14 & Rejected \\
\hline 20 & 0.99 & 0.01 & 1.21 & 0.60 & 0.96 & 2.50 & 0.08 & 0.73 & 1.08 & $\mathrm{OK}$ \\
\hline 21 & 1.00 & 0.00 & 0.91 & 0.26 & 1.00 & 6.68 & 0.00 & 0.75 & 1.18 & Rejected \\
\hline 22 & 0.97 & 0.01 & 2.29 & 0.51 & 0.95 & 9.97 & 0.00 & 0.44 & 0.81 & Rejected \\
\hline 23 & 0.96 & 0.01 & 2.52 & 0.53 & 0.94 & 11.61 & 0.00 & 0.52 & 0.97 & Rejected \\
\hline 24 & 0.96 & 0.01 & 2.33 & 0.49 & 0.93 & 12.18 & 0.00 & 0.65 & 1.37 & Rejected \\
\hline
\end{tabular}

1. Wald test is the test that the coefficient for PWXT $=1$ and the constant $=0$.

2. The effect is calculated at the sample mean and given in euro per MWh difference with the sample mean. Bold coefficients and test-statistics are significant at 5\%.

and a statistical test result indicating that the two series are identical. The reason for this is that the prices in non-peak hours are very stable (see Figure $2 \mathrm{a}$ in the previous section) so that small deviations may have a larger impact on the estimation results. Peak prices vary so much over time that relative small deviations do not impact on the estimated values of coefficients. This is reflected in the value of the $\mathrm{R}^{2}$, which is often lower in peak hours than in non-peak hours. Overall, we conclude from Table 4 that the wholesale electricity prices in Belgian and 
France are somewhat close to each other on many moments, but that there are still some significant differences.

A similar conclusion, applies to a comparison of all other individual countries with respect to one another: these relationships are often less tight than the relationship between Belgian electricity prices and those in France; see Table 5 for details. Full integration is rejected for all country comparisons for nearly all hours. ${ }^{13}$ Sometimes, however, price differences are very small in the majority of time periods.

Table 5. Number of hours for which convergence between wholesale electricity prices in two countries is not rejected

\begin{tabular}{lrrrrrrrrr}
\hline & APX & BELPEX & EEX & EXAA & IPEX & NordPool & Omel & POLPX & PWXT \\
\hline APX & - & 4 & 1 & 1 & 0 & 0 & 0 & 0 & 5 \\
BELPEX & 0 & - & 0 & 0 & 0 & 0 & 0 & 0 & 1 \\
EEX & 0 & 1 & - & 0 & 0 & 0 & 0 & 0 & 1 \\
EXAA & 1 & 5 & 5 & - & 0 & 0 & 0 & 0 & 4 \\
IPEX & 0 & 0 & 0 & 0 & - & 0 & 0 & 0 & 0 \\
NordPool & 0 & 0 & 0 & 0 & 0 & - & 0 & 0 & 0 \\
Omel & 0 & 1 & 0 & 0 & 0 & 0 & - & 0 & 1 \\
POLPX & 1 & 1 & 0 & 0 & 0 & 0 & 0 & - & 1 \\
PWXT & 0 & 4 & 0 & 0 & 0 & 0 & 0 & 0 & - \\
\hline
\end{tabular}

\subsection{Comparing individual country prices with a composite price}

Next, we present the results of a similar analysis as before, but now replacing individual country data by a composite price as explanatory variable, where this composite price is constructed out of the original individual country prices in such a way that at each time period the composite price is the individual country's price that is closest to the price of the country we with to investigate. As explained before, the idea behind this construction is that because of the homogeneity of electricity and the perfect arbitrage possibilities, electricity flows to wherever the price is lowest if there is sufficient interconnection capacity. So, in this way we can test whether there is any moment in time where an individual country's electricity prices are different from any of its neighboring countries. If not, then one can rightfully claim that the wholesale electricity market is always larger than the country itself. To show the results of

\footnotetext{
${ }^{13}$ Full tables are available on request.
} 
this analysis, we again first concentrate on Belgium and report a full set of results for this country and then continue to report the overall results in a more summarizing fashion.

Table 6. Estimation results BELPEX as function of MIX

\begin{tabular}{|c|c|c|c|c|c|c|c|c|c|c|}
\hline & \multicolumn{2}{|c|}{ MIX } & \multicolumn{2}{|c|}{ Constant } & \multicolumn{3}{|c|}{ Wald-test ${ }^{1}$} & \multicolumn{2}{|c|}{ Difference } & \multirow[b]{2}{*}{ Conclusion } \\
\hline & Coeff & St. error & Coeff & St. error & $\mathrm{R}^{2}$ & Wald & Prob. & Effect $^{2}$ & $\%$ mean & \\
\hline 1 & 1.00 & 0.00 & -0.03 & 0.03 & 1.00 & 0.77 & 0.47 & 0.01 & 0.02 & $\mathrm{OK}$ \\
\hline 2 & 1.00 & 0.00 & -0.02 & 0.03 & 1.00 & 0.90 & 0.41 & -0.02 & -0.05 & $\mathrm{OK}$ \\
\hline 3 & 1.00 & 0.00 & 0.00 & 0.03 & 1.00 & 1.10 & 0.33 & -0.02 & -0.05 & OK \\
\hline 4 & 1.00 & 0.00 & 0.06 & 0.03 & 1.00 & 4.20 & 0.02 & -0.02 & -0.06 & Rejected \\
\hline 5 & 1.00 & 0.00 & 0.05 & 0.03 & 1.00 & 4.67 & 0.01 & -0.02 & -0.07 & Rejected \\
\hline 6 & 1.00 & 0.00 & -0.02 & 0.02 & 1.00 & 3.07 & 0.05 & 0.01 & 0.03 & Rejected \\
\hline 7 & 1.00 & 0.00 & -0.01 & 0.05 & 1.00 & 1.29 & 0.28 & 0.03 & 0.08 & $\mathrm{OK}$ \\
\hline 8 & 1.00 & 0.00 & 0.01 & 0.11 & 1.00 & 0.80 & 0.45 & 0.06 & 0.11 & OK \\
\hline 9 & 1.00 & 0.00 & -0.03 & 0.20 & 0.99 & 1.67 & 0.19 & 0.15 & 0.24 & OK \\
\hline 10 & 1.00 & 0.00 & 0.08 & 0.16 & 1.00 & 0.66 & 0.52 & 0.09 & 0.14 & $\mathrm{OK}$ \\
\hline 11 & 1.00 & 0.00 & 0.03 & 0.12 & 1.00 & 1.10 & 0.33 & 0.09 & 0.12 & OK \\
\hline 12 & 1.00 & 0.00 & 0.04 & 0.17 & 1.00 & 0.59 & 0.56 & 0.10 & 0.13 & OK \\
\hline 13 & 1.00 & 0.00 & -0.02 & 0.14 & 1.00 & 1.07 & 0.34 & 0.08 & 0.11 & $\mathrm{OK}$ \\
\hline 14 & 1.00 & 0.00 & 0.26 & 0.20 & 1.00 & 0.97 & 0.38 & 0.02 & 0.03 & $\mathrm{OK}$ \\
\hline 15 & 1.00 & 0.00 & -0.02 & 0.12 & 1.00 & 0.21 & 0.81 & 0.03 & 0.04 & OK \\
\hline 16 & 1.00 & 0.00 & 0.01 & 0.10 & 1.00 & 0.29 & 0.75 & 0.04 & 0.07 & $\mathrm{OK}$ \\
\hline 17 & 1.00 & 0.00 & 0.04 & 0.08 & 1.00 & 0.45 & 0.64 & 0.05 & 0.08 & OK \\
\hline 18 & 1.00 & 0.00 & 0.05 & 0.14 & 1.00 & 1.81 & 0.16 & 0.15 & 0.22 & OK \\
\hline 19 & 1.00 & 0.00 & 0.01 & 0.06 & 1.00 & 0.68 & 0.51 & 0.04 & 0.05 & OK \\
\hline 20 & 1.00 & 0.00 & 0.01 & 0.07 & 1.00 & 0.09 & 0.92 & -0.01 & -0.01 & OK \\
\hline 21 & 1.00 & 0.00 & -0.01 & 0.04 & 1.00 & 0.27 & 0.76 & 0.00 & 0.00 & $\mathrm{OK}$ \\
\hline 22 & 1.00 & 0.00 & -0.08 & 0.08 & 1.00 & 1.65 & 0.19 & 0.04 & 0.07 & $\mathrm{OK}$ \\
\hline 23 & 1.00 & 0.00 & 0.13 & 0.07 & 1.00 & 5.74 & 0.00 & -0.05 & -0.09 & Rejected \\
\hline 24 & 1.00 & 0.00 & 0.02 & 0.06 & 1.00 & 0.54 & 0.58 & 0.02 & 0.05 & OK \\
\hline
\end{tabular}

1. Wald test is the test that the coefficient for PWXT $=1$ and the constant $=0$.

2. The effect is calculated at the sample mean and given in euro per MWh difference with the sample mean. Bold coefficients and test-statistics are significant at 5\%.

Table 6 presents the following interesting results that come out of our analysis. At any moment in time the estimated slope $\beta$ coefficient of Equation (1) is exactly equal to 1.00, whereas the estimated coefficient $\alpha$ coefficient of Equation (1) is close to 0.00 and the null hypothesis that the coefficient equals 0 cannot be rejected for almost any hour. Moreover, for every hour the $\mathrm{R}^{2}$ is exactly equal to 1.00 (or just differs by less than 0.01 ). This means that 
two time series are really almost identical at any moment in time and the statistical Wald-test only rejects the hypothesis that the two series are identical in four of the non-peak hours 4,5 , 6 and 23 (but this is again due to the fact that the time series in these hours are very stable and that therefore any small difference clearly sticks out). Statistical significance in this case also coincides with economic significance: the average price difference in any hour is less than $€ 0.26$ and for most hours it is clearly less than $€ 0.10$ ! We conclude from this that at any point in time there is no separate Belgian wholesale electricity market and that the market is always intimately connected to at least one other country and no electricity company can enjoy market power in a separate Belgian market.

It is of course important to know how the composite MIX index is composed. It turns out that the non-neighboring countries' prices are never used and German prices are almost never used as the basis for the composite price and that both the French and Dutch prices account for around $50 \%$ of the cases (see table 7 below). Therefore, Belgian electricity prices are intimately connected to the corresponding prices of these two neighboring countries.

We next present the results of the same analysis for the other countries to see whether the same result applies to other countries as well. Table 7 reports what the constituent parts for the composite mix price index are for each individual country. Table 8 a reports the overall results for peak hours and table $8 \mathrm{~b}$ presents the results for non-peak hours.

Table 7 shows that for five countries in the dataset, the composite mix price index is mostly composed of the price data in the countries with which it is mostly integrated. For Belgium, these are exclusively France and the Netherlands, and for France and the Netherlands, these are mostly the other two countries for which the markets are coupled. For Austria and Germany most of the connections are with the former three countries and with each other. For the remaining countries the mix does not seem to follow a clear pattern.

Using these composite mixed variables, Tables $8 \mathrm{a}$ and $8 \mathrm{~b}$ then provide the main results of our analysis. ${ }^{14}$ Table 8 a summarizes the main components of the regression results where individual country data for peak hours are explained in terms of the composite MIX data. From the table it is clear that the French and Dutch wholesale electricity prices can be very

\footnotetext{
${ }^{14}$ Full results are included in Appendix B.
} 
well explained by the composite mix variable. The $\mathrm{R}^{2}$ is typically very high, the percentage deviation from the mean is often less than $0.1 \%$ and even if convergence is formally rejected from a statistical point of view (which in the peak hours actually never happens for France), then the difference from the mean is still less than $1 \%$. One can also clearly see that Austria and Germany are also quite well integrated with Belgium, France and the Netherlands, although the convergence is less strong for these two countries as it is for the former three countries. Given the market coupling of the wholesale prices in The Netherlands, France and Belgium this should not be very surprising. ${ }^{15}$ It is clear that for the remaining countries, convergence does not obtain even if we consider the composite mix variable. Convergence is formally rejected for all hours (apart from 2 hours for Poland) and the percentage deviation from the mean can easily be more than $10 \%$.

Table 7. Composition of MIX prices in percentage of total observations

\begin{tabular}{lrrrrrrrrr}
\hline & APX & BELPEX & EEX & EXAA & IPEX & NordPool & Omel & POLPX & PWXT \\
\hline APX & 0 & 34 & 24 & 14 & 10 & 3 & 7 & 12 & 68 \\
BELPEX & 34 & 0 & 3 & 1 & 1 & 0 & 1 & 2 & 21 \\
EEX & 4 & 0 & 0 & 27 & 14 & 15 & 13 & 16 & 3 \\
EXAA & 8 & 0 & 33 & 0 & 14 & 14 & 10 & 15 & 3 \\
IPEX & 2 & 0 & 6 & 5 & 0 & 3 & 13 & 5 & 1 \\
NordPool & 1 & 0 & 11 & 8 & 5 & 0 & 13 & 24 & 1 \\
Omel & 2 & 0 & 12 & 8 & 31 & 17 & 0 & 27 & 2 \\
POLPX & 2 & 0 & 3 & 11 & 10 & 36 & 28 & 0 & 1 \\
PWXT & 46 & 65 & 7 & 26 & 15 & 11 & 15 & 0 & 0 \\
Total & 100 & 100 & 100 & 100 & 100 & 100 & 100 & 100 & 100 \\
\hline
\end{tabular}

The analysis in Table $8 \mathrm{~b}$ for non-peak hours confirms the results for peak hours. Even though for some hours, the formal test of convergence is rejected for France and the Netherlands, the $\mathrm{R}^{2}$ is typically 0.99 or higher and the percentage deviation from the mean is usually as small as $0.1 \%$. Austria and Germany are also well integrated with at least one other country indicating that there is a group of roughly five countries that can be said to form the forefront of the integration of European wholesale electricity markets. Our methodology of looking at a composite index with which a country is integrated does not help for the remaining countries (Italy, Spain, Poland and the Scandinavian countries): even with the composite index, convergence should be rejected.

\footnotetext{
${ }^{15}$ Using electricity price data for the United States, Park et al. (2006) shows that a similar institutional framework (like trading structures) rather than physical connections explains integration of some markets.
} 
Table 8a. Estimation results for peak hours for all countries as function of their MIX

\begin{tabular}{|c|c|c|c|c|c|c|c|c|c|c|c|c|c|}
\hline & & 9 & 10 & 11 & 12 & 13 & 14 & 15 & 16 & 17 & 18 & 19 & 20 \\
\hline \multirow[t]{3}{*}{ APX } & $\mathrm{R}^{2}$ & 1.00 & 0.99 & 0.99 & 0.95 & 0.94 & 0.95 & 0.98 & 0.98 & 1.00 & 0.99 & 0.99 & 0.98 \\
\hline & $\%$ mean $^{1}$ & 0.04 & 0.57 & 0.89 & 1.30 & 0.93 & 0.96 & 0.60 & 0.86 & 0.32 & 0.42 & 0.14 & 0.39 \\
\hline & Conclusion $^{2}$ & $\mathrm{OK}$ & $\mathrm{R}$ & $\mathrm{R}$ & $\mathrm{R}$ & $\mathrm{OK}$ & $\mathrm{OK}$ & $\mathrm{OK}$ & $\mathrm{OK}$ & $\mathrm{R}$ & $\mathrm{R}$ & $\mathrm{R}$ & $\mathrm{OK}$ \\
\hline \multirow[t]{3}{*}{ EEX } & $\mathrm{R}^{2}$ & 0.72 & 0.94 & 0.92 & 0.68 & 0.84 & 0.86 & 0.88 & 0.97 & 0.97 & 0.77 & 0.59 & 0.86 \\
\hline & $\%$ mean & 2.12 & -0.02 & 0.44 & 3.71 & 1.33 & 0.76 & 0.23 & -1.18 & -0.98 & 0.77 & 2.49 & 0.29 \\
\hline & Conclusion & OK & $\mathrm{OK}$ & $\mathrm{OK}$ & $\mathrm{R}$ & $\mathrm{R}$ & $\mathrm{OK}$ & $\mathrm{OK}$ & $\mathrm{R}$ & $\mathrm{R}$ & $\mathrm{OK}$ & $\mathrm{OK}$ & $\mathrm{OK}$ \\
\hline \multirow[t]{3}{*}{ EXAA } & $\mathrm{R}^{2}$ & 0.98 & 0.98 & 0.99 & 0.98 & 0.98 & 0.99 & 0.98 & 0.99 & 0.98 & 0.96 & 0.98 & 0.97 \\
\hline & $\%$ mean & 0.24 & -0.13 & -0.02 & 0.37 & 0.59 & 0.03 & -0.40 & -0.17 & 0.03 & 1.90 & 0.88 & 0.57 \\
\hline & Conclusion & OK & $\mathrm{R}$ & $\mathrm{R}$ & OK & $\mathrm{R}$ & OK & $\mathrm{R}$ & OK & $\mathrm{R}$ & $\mathrm{R}$ & $\mathrm{R}$ & $\mathrm{R}$ \\
\hline \multirow[t]{3}{*}{ IPEX } & $\mathrm{R}^{2}$ & 0.56 & 0.30 & 0.26 & 0.36 & 0.50 & 0.58 & 0.39 & 0.28 & 0.28 & 0.49 & 0.51 & 0.57 \\
\hline & $\%$ mean & 32.89 & 49.80 & 50.66 & 36.83 & 22.46 & 19.95 & 30.08 & 44.32 & 55.44 & 44.89 & 38.43 & 34.08 \\
\hline & Conclusion & $\mathrm{R}$ & $\mathrm{R}$ & $\mathrm{R}$ & $\mathrm{R}$ & $\mathrm{R}$ & $\mathrm{R}$ & $\mathrm{R}$ & $\mathrm{R}$ & $\mathrm{R}$ & $\mathrm{R}$ & $\mathrm{R}$ & $\mathrm{R}$ \\
\hline \multirow[t]{3}{*}{ NordPool } & $\mathrm{R}^{2}$ & 0.78 & 0.73 & 0.70 & 0.70 & 0.69 & 0.69 & 0.70 & 0.71 & 0.74 & 0.73 & 0.69 & 0.65 \\
\hline & $\%$ mean & -10.18 & -14.31 & -16.39 & -18.54 & -19.81 & -19.12 & -16.75 & -15.40 & -14.87 & -14.69 & -17.86 & -20.38 \\
\hline & Conclusion & $\mathrm{R}$ & $\mathrm{R}$ & $\mathrm{R}$ & $\mathrm{R}$ & $\mathrm{R}$ & $\mathrm{R}$ & $\mathrm{R}$ & $\mathrm{R}$ & $\mathrm{R}$ & $\mathrm{R}$ & $\mathrm{R}$ & $\mathrm{R}$ \\
\hline \multirow[t]{3}{*}{ Omel } & $\mathrm{R}^{2}$ & 0.91 & 0.90 & 0.88 & 0.87 & 0.89 & 0.90 & 0.90 & 0.91 & 0.89 & 0.87 & 0.84 & 0.87 \\
\hline & $\%$ mean & 2.36 & 2.47 & 3.72 & 2.70 & 2.64 & 3.15 & 2.24 & 2.40 & 3.58 & 3.38 & 3.34 & 2.91 \\
\hline & Conclusion & $\mathrm{R}$ & $\mathrm{R}$ & $\mathrm{R}$ & $\mathrm{R}$ & $\mathrm{R}$ & $\mathrm{R}$ & $\mathrm{R}$ & $\mathrm{R}$ & $\mathrm{R}$ & $\mathrm{R}$ & $\mathrm{R}$ & $\mathrm{R}$ \\
\hline \multirow[t]{3}{*}{ POLPX } & $\mathrm{R}^{2}$ & 0.79 & 0.85 & 0.86 & 0.87 & 0.89 & 0.89 & 0.88 & 0.86 & 0.66 & 0.46 & 0.30 & 0.20 \\
\hline & $\%$ mean & 4.05 & -0.17 & -0.14 & -1.81 & -2.30 & -3.64 & -1.48 & -6.60 & -17.68 & -24.59 & -44.53 & -52.56 \\
\hline & Conclusion & $\mathrm{R}$ & $\mathrm{OK}$ & OK & $\mathrm{R}$ & $\mathrm{R}$ & $\mathrm{R}$ & $\mathrm{R}$ & $\mathrm{R}$ & $\mathrm{R}$ & $\mathrm{R}$ & $\mathrm{R}$ & $\mathrm{R}$ \\
\hline \multirow[t]{3}{*}{ PWXT } & $\mathrm{R}^{2}$ & 1.00 & 1.00 & 1.00 & 1.00 & 1.00 & 1.00 & 1.00 & 1.00 & 1.00 & 1.00 & 1.00 & 1.00 \\
\hline & $\%$ mean & -0.18 & -0.16 & -0.09 & -0.05 & -0.03 & 0.05 & 0.04 & -0.11 & -0.01 & -0.17 & -0.12 & 0.08 \\
\hline & Conclusion & $\mathrm{OK}$ & $\mathrm{OK}$ & $\mathrm{OK}$ & OK & OK & OK & $\mathrm{OK}$ & $\mathrm{OK}$ & OK & $\mathrm{OK}$ & $\mathrm{OK}$ & OK \\
\hline
\end{tabular}

1. The percentage mean $(\%$ mean $)$ is calculated as $=\frac{\alpha+(\beta-1) * \text { mean }\left(M i x_{h, t}\right)}{\operatorname{mean}\left(\operatorname{Mix}_{h, t}\right)}$. Where $\alpha$ and $\beta$ are the estimated coefficients. 2. The letter R means rejected. 
Table 8b. Estimation results for non-peak hours for all countries as function of their MIX

\begin{tabular}{|c|c|c|c|c|c|c|c|c|c|c|c|c|c|}
\hline & & 1 & 2 & 3 & 4 & 5 & 6 & 7 & 8 & 21 & 22 & 23 & 24 \\
\hline \multirow[t]{3}{*}{ APX } & $\mathrm{R}^{2}$ & 0.93 & 0.99 & 0.99 & 0.99 & 0.99 & 0.99 & 1.00 & 1.00 & 0.99 & 0.99 & 1.00 & 0.99 \\
\hline & $\%$ mean $^{1}$ & 0.57 & 0.17 & -0.16 & 0.11 & -0.10 & 0.02 & 0.07 & -0.20 & 0.07 & 0.17 & -0.03 & 0.24 \\
\hline & Conclusion $^{2}$ & $\mathrm{R}$ & $\mathrm{OK}$ & $\mathrm{OK}$ & $\mathrm{OK}$ & $\mathrm{OK}$ & $\mathrm{OK}$ & $\mathrm{OK}$ & $\mathrm{R}$ & $\mathrm{R}$ & $\mathrm{R}$ & $\mathrm{OK}$ & $\mathrm{R}$ \\
\hline \multirow[t]{3}{*}{ EEX } & $\mathrm{R}^{2}$ & 0.95 & 0.94 & 0.92 & 0.90 & 0.90 & 0.93 & 0.95 & 0.87 & 0.97 & 0.97 & 0.97 & 0.96 \\
\hline & $\%$ mean & -1.25 & -2.53 & -3.15 & -4.06 & -2.18 & 0.09 & -0.69 & 0.80 & -0.24 & -0.85 & -0.85 & -2.30 \\
\hline & Conclusion & $\mathrm{R}$ & $\mathrm{R}$ & $\mathrm{R}$ & $\mathrm{R}$ & $\mathrm{R}$ & $\mathrm{OK}$ & $\mathrm{R}$ & OK & OK & $\mathrm{R}$ & $\mathrm{R}$ & $\mathrm{R}$ \\
\hline \multirow[t]{3}{*}{ EXAA } & $\mathrm{R}^{2}$ & 0.98 & 0.97 & 0.97 & 0.96 & 0.97 & 0.97 & 0.98 & 0.99 & 0.99 & 0.99 & 0.98 & 0.98 \\
\hline & $\%$ mean & -1.11 & -1.39 & -1.86 & -1.68 & -0.60 & -0.57 & -0.22 & 0.32 & 0.41 & 0.09 & 0.05 & -0.85 \\
\hline & Conclusion & $\mathrm{R}$ & $\mathrm{R}$ & $\mathrm{R}$ & $\mathrm{R}$ & $\mathrm{OK}$ & $\mathrm{OK}$ & OK & OK & OK & $\mathrm{OK}$ & OK & $\mathrm{R}$ \\
\hline \multirow[t]{3}{*}{ IPEX } & $\mathrm{R}^{2}$ & 0.75 & 0.79 & 0.82 & 0.82 & 0.79 & 0.79 & 0.77 & 0.75 & 0.54 & 0.44 & 0.69 & 0.68 \\
\hline & $\%$ mean & 13.13 & 10.38 & 8.42 & 7.99 & 8.19 & 10.82 & 18.59 & 17.99 & 37.11 & 29.96 & 17.34 & 15.69 \\
\hline & Conclusion & $\mathrm{R}$ & $\mathrm{R}$ & $\mathrm{R}$ & $\mathrm{R}$ & $\mathrm{R}$ & $\mathrm{R}$ & $\mathrm{R}$ & $\mathrm{R}$ & $\mathrm{R}$ & $\mathrm{R}$ & $\mathrm{R}$ & $\mathrm{R}$ \\
\hline \multirow[t]{3}{*}{ NordPool } & $\mathrm{R}^{2}$ & 0.75 & 0.84 & 0.88 & 0.90 & 0.92 & 0.90 & 0.84 & 0.84 & 0.67 & 0.72 & 0.70 & 0.71 \\
\hline & $\%$ mean & -10.74 & -6.39 & -3.58 & -1.27 & -0.30 & -3.36 & -7.39 & -6.87 & -20.53 & -16.39 & -16.77 & -12.78 \\
\hline & Conclusion & $\mathrm{R}$ & $\mathrm{R}$ & $\mathrm{R}$ & OK & OK & $\mathrm{R}$ & $\mathrm{R}$ & $\mathrm{R}$ & $\mathrm{R}$ & $\mathrm{R}$ & $\mathrm{R}$ & $\mathrm{R}$ \\
\hline \multirow[t]{3}{*}{ Omel } & $\mathrm{R}^{2}$ & 0.84 & 0.86 & 0.85 & 0.82 & 0.83 & 0.87 & 0.91 & 0.91 & 0.87 & 0.88 & 0.90 & 0.89 \\
\hline & $\%$ mean & 5.03 & 5.78 & 5.70 & 7.16 & 6.81 & 3.71 & 1.23 & 2.82 & 2.99 & 3.10 & 2.79 & 3.28 \\
\hline & Conclusion & $\mathrm{R}$ & $\mathrm{R}$ & $\mathrm{R}$ & $\mathrm{R}$ & $\mathrm{R}$ & $\mathrm{R}$ & $\mathrm{R}$ & $\mathrm{R}$ & $\mathrm{R}$ & $\mathrm{R}$ & $\mathrm{R}$ & $\mathrm{R}$ \\
\hline \multirow[t]{3}{*}{ POLPX } & $\mathrm{R}^{2}$ & 0.78 & 0.71 & 0.64 & 0.49 & 0.43 & 0.40 & 0.46 & 0.65 & 0.27 & 0.49 & 0.61 & 0.73 \\
\hline & $\%$ mean & 6.83 & 35.80 & 48.96 & 80.97 & 100.82 & 66.41 & 30.89 & 17.34 & -48.89 & -40.03 & -33.46 & -13.64 \\
\hline & Conclusion & $\mathrm{R}$ & $\mathrm{R}$ & $\mathrm{R}$ & $\mathrm{R}$ & $\mathrm{R}$ & $\mathrm{R}$ & $\mathrm{R}$ & $\mathrm{R}$ & $\mathrm{R}$ & $\mathrm{R}$ & $\mathrm{R}$ & $\mathrm{R}$ \\
\hline \multirow[t]{3}{*}{ PWXT } & $\mathrm{R}^{2}$ & 0.99 & 0.99 & 0.99 & 1.00 & 0.99 & 0.99 & 0.99 & 0.99 & 1.00 & 1.00 & 1.00 & 0.99 \\
\hline & $\%$ mean & -0.16 & 0.13 & 0.45 & -0.13 & -0.86 & -0.20 & -0.46 & -0.36 & -0.01 & 0.15 & 0.12 & 0.15 \\
\hline & Conclusion & $\mathrm{OK}$ & $\mathrm{OK}$ & $\mathrm{R}$ & $\mathrm{OK}$ & $\mathrm{R}$ & OK & $\mathrm{R}$ & $\mathrm{OK}$ & $\mathrm{OK}$ & $\mathrm{OK}$ & OK & $\mathrm{OK}$ \\
\hline
\end{tabular}

1 The percentage mean $(\%$ mean $)$ is calculated as $=\frac{\alpha+(\beta-1) * \text { mean }\left(M i x_{h, t}\right)}{\operatorname{mean}\left(\operatorname{Mix}_{h, t}\right)}$. Where $\alpha$ and $\beta$ are the estimated coefficients. 2. The letter R means rejected. 
Table 9a. Estimation results for peak hours for all countries as function of their MIX: first differences

\begin{tabular}{|c|c|c|c|c|c|c|c|c|c|c|c|c|c|}
\hline & & 9 & 10 & 11 & 12 & 13 & 14 & 15 & 16 & 17 & 18 & 19 & 20 \\
\hline \multirow[t]{3}{*}{ APX } & $\mathrm{R}^{2}$ & 0.96 & 0.97 & 0.97 & 0.94 & 0.87 & 0.90 & 0.96 & 0.96 & 0.98 & 0.99 & 0.98 & 0.94 \\
\hline & $\%$ mean $^{1}$ & 0.76 & 0.48 & -0.02 & -0.41 & 1.29 & 0.74 & 0.55 & 0.62 & 0.26 & 2.47 & -0.74 & 1.26 \\
\hline & Conclusion $^{2}$ & $\mathrm{OK}$ & OK & $\mathrm{OK}$ & $\mathrm{OK}$ & $\mathrm{OK}$ & $\mathrm{OK}$ & OK & OK & $\mathrm{OK}$ & $\mathrm{R}$ & OK & OK \\
\hline \multirow[t]{3}{*}{ BELPEX } & $\mathrm{R}^{2}$ & 0.99 & 1.00 & 1.00 & 1.00 & 1.00 & 0.99 & 1.00 & 1.00 & 1.00 & 1.00 & 1.00 & 1.00 \\
\hline & $\%$ mean & -0.07 & -0.24 & -0.11 & -0.12 & -0.09 & -0.74 & -0.01 & -0.07 & -0.09 & -0.08 & -0.02 & -0.03 \\
\hline & Conclusion & $\mathrm{OK}$ & $\mathrm{OK}$ & $\mathrm{OK}$ & OK & OK & $\mathrm{OK}$ & $\mathrm{OK}$ & $\mathrm{OK}$ & $\mathrm{OK}$ & $\mathrm{OK}$ & $\mathrm{OK}$ & OK \\
\hline \multirow[t]{3}{*}{ EEX } & $\mathrm{R}^{2}$ & 0.50 & 0.86 & 0.83 & 0.50 & 0.63 & 0.68 & 0.73 & 0.89 & 0.90 & 0.70 & 0.45 & 0.72 \\
\hline & $\%$ mean & -12.13 & -2.64 & -5.13 & -12.88 & -14.75 & -7.01 & -6.48 & -4.56 & -3.45 & -5.68 & -12.98 & -3.24 \\
\hline & Conclusion & $\mathrm{R}$ & $\mathrm{OK}$ & $\mathrm{R}$ & $\mathrm{R}$ & $\mathrm{R}$ & $\mathrm{R}$ & $\mathrm{R}$ & $\mathrm{R}$ & $\mathrm{R}$ & $\mathrm{OK}$ & $\mathrm{R}$ & $\mathrm{OK}$ \\
\hline \multirow[t]{3}{*}{ EXAA } & $\mathrm{R}^{2}$ & 0.95 & 0.95 & 0.96 & 0.95 & 0.95 & 0.95 & 0.95 & 0.95 & 0.96 & 0.95 & 0.97 & 0.94 \\
\hline & $\%$ mean & -3.30 & -6.21 & -5.67 & -2.86 & -0.95 & -1.66 & -3.64 & -2.69 & -3.10 & 1.62 & -1.25 & 2.58 \\
\hline & Conclusion & $\mathrm{R}$ & $\mathrm{R}$ & $\mathrm{R}$ & $\mathrm{R}$ & $\mathrm{R}$ & $\mathrm{R}$ & $\mathrm{R}$ & $\mathrm{R}$ & $\mathrm{R}$ & $\mathrm{R}$ & $\mathrm{R}$ & $\mathrm{R}$ \\
\hline \multirow[t]{3}{*}{ IPEX } & $\mathrm{R}^{2}$ & 0.42 & 0.23 & 0.21 & 0.30 & 0.31 & 0.42 & 0.28 & 0.23 & 0.29 & 0.48 & 0.48 & 0.45 \\
\hline & $\%$ mean & -48.60 & -74.42 & -76.96 & -61.58 & -46.29 & -33.44 & -42.79 & -47.86 & -51.68 & -48.74 & -46.82 & -45.49 \\
\hline & Conclusion & $\mathrm{R}$ & $\mathrm{R}$ & $\mathrm{R}$ & $\mathrm{R}$ & $\mathrm{R}$ & $\mathrm{R}$ & $\mathrm{R}$ & $\mathrm{R}$ & $\mathrm{R}$ & $\mathrm{R}$ & $\mathrm{R}$ & $\mathrm{R}$ \\
\hline \multirow[t]{3}{*}{ NordPool } & $\mathrm{R}^{2}$ & 0.27 & 0.15 & 0.12 & 0.10 & 0.11 & 0.14 & 0.13 & 0.16 & 0.18 & 0.14 & 0.06 & 0.02 \\
\hline & $\%$ mean & -25.39 & -32.50 & -36.40 & -37.43 & -37.24 & -35.22 & -33.46 & -32.35 & -31.71 & -33.67 & -42.42 & -45.06 \\
\hline & Conclusion & $\mathrm{R}$ & $\mathrm{R}$ & $\mathrm{R}$ & $\mathrm{R}$ & $\mathrm{R}$ & $\mathrm{R}$ & $\mathrm{R}$ & $\mathrm{R}$ & $\mathrm{R}$ & $\mathrm{R}$ & $\mathrm{R}$ & $\mathrm{R}$ \\
\hline \multirow[t]{3}{*}{ Omel } & $\mathrm{R}^{2}$ & 0.61 & 0.56 & 0.51 & 0.50 & 0.51 & 0.52 & 0.50 & 0.54 & 0.51 & 0.50 & 0.48 & 0.63 \\
\hline & $\%$ mean & -7.18 & -9.97 & -16.54 & -18.64 & -18.64 & -17.70 & -14.84 & -11.07 & -10.91 & -13.54 & -18.97 & -19.42 \\
\hline & Conclusion & $\mathrm{R}$ & $\mathrm{R}$ & $\mathrm{R}$ & $\mathrm{R}$ & $\mathrm{R}$ & $\mathrm{R}$ & $\mathrm{R}$ & $\mathrm{R}$ & $\mathrm{R}$ & $\mathrm{R}$ & $\mathrm{R}$ & $\mathrm{R}$ \\
\hline \multirow[t]{3}{*}{ POLPX } & $\mathrm{R}^{2}$ & 0.18 & 0.29 & 0.36 & 0.42 & 0.51 & 0.51 & 0.38 & 0.21 & 0.05 & 0.03 & 0.02 & 0.13 \\
\hline & $\%$ mean & -25.39 & -21.22 & -19.81 & -20.47 & -16.04 & -14.09 & -15.87 & -21.84 & -24.41 & -32.35 & -28.44 & -40.47 \\
\hline & Conclusion & $\mathrm{R}$ & $\mathrm{R}$ & $\mathrm{R}$ & $\mathrm{R}$ & $\mathrm{R}$ & $\mathrm{R}$ & $\mathrm{R}$ & $\mathrm{R}$ & $\mathrm{R}$ & $\mathrm{R}$ & $\mathrm{R}$ & $\mathrm{R}$ \\
\hline \multirow[t]{3}{*}{ PWXT } & $\mathrm{R}^{2}$ & 0.99 & 0.99 & 0.99 & 0.99 & 0.99 & 0.99 & 0.99 & 0.99 & 0.99 & 1.00 & 1.00 & 1.00 \\
\hline & $\%$ mean & -0.05 & 0.07 & -0.13 & -0.69 & -0.69 & -0.81 & -0.78 & -0.31 & -0.14 & 0.11 & -0.09 & -0.40 \\
\hline & Conclusion & OK & OK & $\mathrm{OK}$ & $\mathrm{OK}$ & $\mathrm{OK}$ & $\mathrm{OK}$ & OK & $\mathrm{OK}$ & $\mathrm{OK}$ & OK & OK & $\mathrm{OK}$ \\
\hline
\end{tabular}

1. The percentage mean (\% mean) is calculated as $=\frac{\alpha+(\beta-1) * \operatorname{stdev}(\operatorname{Mix} h, t)}{\operatorname{stdev}\left(\operatorname{Mix}_{h, t}\right)}$. Where $\alpha$ and $\beta$ are the estimated coefficients. 2. The letter R means rejected. 
Table 9b. Estimation results for non-peak hours for all countries as function of their MIX: first differences

\begin{tabular}{|c|c|c|c|c|c|c|c|c|c|c|c|c|c|}
\hline & & 1 & 2 & 3 & 4 & 5 & 6 & 7 & 8 & 21 & 22 & 23 & 24 \\
\hline \multirow[t]{3}{*}{ APX } & $\mathrm{R}^{2}$ & 0.69 & 0.79 & 0.82 & 0.84 & 0.83 & 0.82 & 0.88 & 0.94 & 0.88 & 0.81 & 0.77 & 0.67 \\
\hline & $\%$ mean $^{1}$ & 4.90 & 2.13 & 2.00 & 0.86 & 0.92 & 1.39 & 1.60 & 0.69 & -0.82 & -0.11 & -4.44 & -6.17 \\
\hline & Conclusion $^{2}$ & $\mathrm{R}$ & $\mathrm{R}$ & $\mathrm{R}$ & $\mathrm{R}$ & $\mathrm{R}$ & $\mathrm{OK}$ & $\mathrm{OK}$ & OK & $\mathrm{OK}$ & OK & $\mathrm{R}$ & $\mathrm{R}$ \\
\hline \multirow[t]{3}{*}{ BELPEX } & $\mathrm{R}^{2}$ & 1.00 & 1.00 & 1.00 & 1.00 & 1.00 & 1.00 & 1.00 & 0.99 & 1.00 & 1.00 & 1.00 & 1.00 \\
\hline & $\%$ mean & 0.13 & 0.04 & 0.03 & 0.09 & 0.12 & 0.00 & -0.11 & -0.20 & 0.02 & 0.05 & -0.47 & -0.01 \\
\hline & Conclusion & $\mathrm{OK}$ & $\mathrm{OK}$ & $\mathrm{OK}$ & $\mathrm{OK}$ & $\mathrm{R}$ & OK & $\mathrm{OK}$ & $\mathrm{OK}$ & $\mathrm{OK}$ & $\mathrm{OK}$ & $\mathrm{R}$ & OK \\
\hline \multirow[t]{3}{*}{ EEX } & $\mathrm{R}^{2}$ & 0.72 & 0.74 & 0.76 & 0.73 & 0.72 & 0.72 & 0.82 & 0.74 & 0.85 & 0.77 & 0.72 & 0.58 \\
\hline & $\%$ mean & -0.43 & 0.55 & 1.07 & 1.84 & -0.51 & -4.51 & -0.76 & -1.98 & -3.84 & -5.55 & -4.40 & -6.17 \\
\hline & Conclusion & $\mathrm{OK}$ & $\mathrm{OK}$ & $\mathrm{R}$ & $\mathrm{R}$ & $\mathrm{R}$ & $\mathrm{R}$ & $\mathrm{OK}$ & $\mathrm{OK}$ & $\mathrm{R}$ & $\mathrm{R}$ & $\mathrm{R}$ & $\mathrm{R}$ \\
\hline \multirow[t]{3}{*}{ EXAA } & $\mathrm{R}^{2}$ & 0.82 & 0.83 & 0.85 & 0.88 & 0.88 & 0.87 & 0.92 & 0.96 & 0.93 & 0.86 & 0.79 & 0.71 \\
\hline & $\%$ mean & -3.28 & -2.42 & -0.88 & -0.15 & -1.45 & -2.67 & -2.43 & -1.51 & -3.22 & -3.86 & -5.20 & -6.09 \\
\hline & Conclusion & $\mathrm{R}$ & $\mathrm{R}$ & $\mathrm{R}$ & $\mathrm{R}$ & $\mathrm{R}$ & $\mathrm{R}$ & $\mathrm{R}$ & $\mathrm{R}$ & $\mathrm{R}$ & $\mathrm{R}$ & $\mathrm{R}$ & $\mathrm{R}$ \\
\hline \multirow[t]{3}{*}{ IPEX } & $\mathrm{R}^{2}$ & 0.38 & 0.48 & 0.50 & 0.54 & 0.51 & 0.49 & 0.52 & 0.60 & 0.33 & 0.17 & 0.32 & 0.27 \\
\hline & $\%$ mean & -10.53 & 1.29 & 7.58 & 10.89 & 11.52 & 4.96 & -9.38 & -23.46 & -56.12 & -53.02 & -28.10 & -23.63 \\
\hline & Conclusion & $\mathrm{R}$ & $\mathrm{R}$ & $\mathrm{R}$ & $\mathrm{R}$ & $\mathrm{R}$ & $\mathrm{R}$ & $\mathrm{R}$ & $\mathrm{R}$ & $\mathrm{R}$ & $\mathrm{R}$ & $\mathrm{R}$ & $\mathrm{R}$ \\
\hline \multirow[t]{3}{*}{ NordPool } & $\mathrm{R}^{2}$ & 0.13 & 0.20 & 0.26 & 0.30 & 0.34 & 0.38 & 0.34 & 0.22 & 0.04 & 0.13 & 0.13 & 0.10 \\
\hline & $\%$ mean & -31.86 & -29.96 & -27.67 & -27.10 & -27.74 & -27.83 & -29.20 & -29.87 & -42.98 & -33.73 & -32.83 & -33.63 \\
\hline & Conclusion & $\mathrm{R}$ & $\mathrm{R}$ & $\mathrm{R}$ & $\mathrm{R}$ & $\mathrm{R}$ & $\mathrm{R}$ & $\mathrm{R}$ & $\mathrm{R}$ & $\mathrm{R}$ & $\mathrm{R}$ & $\mathrm{R}$ & $\mathrm{R}$ \\
\hline \multirow[t]{3}{*}{ Omel } & $\mathrm{R}^{2}$ & 0.35 & 0.32 & 0.30 & 0.32 & 0.37 & 0.38 & 0.44 & 0.55 & 0.58 & 0.54 & 0.48 & 0.49 \\
\hline & $\%$ mean & -15.44 & -12.38 & -6.35 & -4.46 & -1.82 & -1.46 & -4.22 & -7.40 & -20.55 & -25.75 & -20.54 & -15.02 \\
\hline & Conclusion & $\mathrm{R}$ & $\mathrm{R}$ & $\mathrm{R}$ & $\mathrm{R}$ & $\mathrm{R}$ & $\mathrm{R}$ & $\mathrm{R}$ & $\mathrm{R}$ & $\mathrm{R}$ & $\mathrm{R}$ & $\mathrm{R}$ & $\mathrm{R}$ \\
\hline \multirow[t]{3}{*}{ POLPX } & $\mathrm{R}^{2}$ & 0.01 & 0.00 & 0.00 & 0.04 & 0.01 & 0.03 & 0.13 & 0.17 & 0.26 & 0.16 & 0.13 & 0.05 \\
\hline & $\%$ mean & -32.69 & -48.06 & -50.13 & -74.86 & -85.93 & -65.04 & -31.47 & -31.49 & -44.00 & -33.67 & -37.31 & -35.26 \\
\hline & Conclusion & $\mathrm{R}$ & $\mathrm{R}$ & $\mathrm{R}$ & $\mathrm{R}$ & $\mathrm{R}$ & $\mathrm{R}$ & $\mathrm{R}$ & $\mathrm{R}$ & $\mathrm{R}$ & $\mathrm{R}$ & $\mathrm{R}$ & $\mathrm{R}$ \\
\hline \multirow[t]{3}{*}{ PWXT } & $\mathrm{R}^{2}$ & 0.95 & 0.96 & 0.95 & 0.97 & 0.96 & 0.96 & 0.96 & 0.98 & 1.00 & 0.97 & 0.96 & 0.95 \\
\hline & $\%$ mean & 2.27 & 0.89 & -0.36 & -0.10 & 0.56 & -0.22 & 0.73 & -0.14 & -0.17 & -0.52 & 0.89 & 0.93 \\
\hline & Conclusion & $\mathrm{R}$ & $\mathrm{R}$ & $\mathrm{R}$ & $\mathrm{OK}$ & $\mathrm{OK}$ & $\mathrm{OK}$ & $\mathrm{OK}$ & $\mathrm{OK}$ & $\mathrm{OK}$ & OK & $\mathrm{OK}$ & $\mathrm{R}$ \\
\hline
\end{tabular}

1. The percentage mean $(\%$ mean $)$ is calculated as $=\frac{\alpha+(\beta-1) * \operatorname{stdev}\left(\operatorname{Mix}_{h, t}\right)}{\operatorname{stdev}(\operatorname{Mix} h, t)}$. Where $\alpha$ and $\beta$ are the estimated coefficients. 2. The letter R means rejected. 


\subsection{Analysis in first-differences}

As a robustness check, we have also done a similar analysis using first-order differences rather than the original time series in absolute values. A first-order difference analysis is appropriate especially in case the time series are not stationary. Above, we have argued that the Dickey-Fuller test tells us that stationarity cannot be rejected for most time series. Nevertheless, the analysis in first-order differences can be used as a robustness check. The results of this analysis are reported in Tables $9 \mathrm{a}$ and $9 \mathrm{~b} .{ }^{16}$ Table 9 confirms the overall picture of Table 8, but makes the distinction between the three groups of countries even more pronounced. For the Belgian market, there are now only two non-peak hours where the formal test of convergence is rejected and we therefore conclude that the Belgian market is almost fully integrated with the Dutch and French markets and this market should not be analyzed in isolation of other markets at any time of the day. Indeed, the $\mathrm{R}^{2}$ is also 1.00 in the two cases where convergence is rejected. Also for France and The Netherlands, the conclusion is that almost at any hour there is another country that imposes a competitive constraint. For the important peak hours, this is true in all hours, apart from one for The Netherlands. The results for Austria and Germany show, however, that the case for convergence is more problematic than it seems to be the case for the analysis in absolute terms presented in Table 8 . Convergence has to be rejected for almost all hours, especially for Austria. The results for the remaining countries confirm the idea that they are not integrated with the rest of Europe.

\section{Conclusion}

In this paper we have argued that one has to be careful in defining electricity wholesale markets in Europe. Standard techniques of market definition suggest that the researcher investigates whether the conditions under which product B is provided impose a competitive constraint on the pricing behavior of firms producing product A. And similarly for products $\mathrm{C}, \mathrm{D}$, etc. If no such a product would impose a competitive constraint, then it is argued that product $\mathrm{A}$ is to be regarded as being in a separate market. If we would apply this line of argument to the European wholesale electricity market, one would conclude that each country constitutes its own separate market. Or, more precisely, there are significant parts of the day where the market in a country behaves differently from markets in each of its neighboring countries. If one takes into account the possibility that product B or C (at least one of them at each moment in time) impose a competitive constraint on the pricing behavior of firms

\footnotetext{
${ }^{16}$ The absolute value of the average price difference as reported in Table 5 is not given in Table 6 as the average of the first difference is (nearly) zero in all cases.
} 
producing product $\mathrm{A}$, then our analysis clearly shows that Belgium should not be regarded as having a separate wholesale electricity market. The same conclusion applies, but a little less strongly, to France and The Netherlands. The results for Austria and Germany are more ambiguous and depend on whether the analysis is carried our in absolute numbers or in first differences. On the basis of our results one can conclude that the wholesale electricity markets of the countries that have coupled their markets (Belgium, France and The Netherlands) should be considered as one and at the forefront of one European wholesale electricity market with Austria and Germany following at some distance.

Our analysis has thus two important conclusions. It points at a weakness of the standard approach towards market definition, especially when applied to wholesale electricity markets. Our alternative is to take a mix of countries into account when considering whether these countries together can impose a competitive constraint. Moreover, at a more substantial level it argues that it is misleading to analyze the wholesale electricity market in quite a few individual member states (in particular Belgium and neighboring countries) as if it is a market that is separated from its neighbors. 


\section{References}

Armstrong M, Galli A. Are day-ahead prices for electricity converging in continental Europe? An exploratory data approach. CERNA Working Paper, Ecole Nationale Supérieure des Mines; 2005.

Bosco B, Parisio L, Pelagatti M, Baldi F. Deregulated wholesale electricity prices in Europe. University of Milano; 2006.

CESI. Cross-border tie-lines within the European power pools, Appendix 1. CESI, Ramboll, Mercados, Comillas; 2005.

$\mathrm{EU}$, Commission notice on the definition of relevant market for the purpose of Community competition law, Official Journal C 372, 9 December 1997, 0005 - 0013.

Greene WH. Econometric Analysis. Prentice-Hall Inc; Englewood Cliffs NJ; 2000.

Huisman R, Mahieu R., Regime jumps in electricity prices. Energy Economics 2003;25;425434.

Knittel CR, Roberts MR. An empirical examination of restructured electricity prices. Energy Economics 2005;27;791-817.

MacKinnon JG. Numerical distribution functions for unit root and cointegration tests. Journal of Applied Econometrics 1996;11;601-618.

Mount TD, Ning Y, Cai X. Predicting price spikes in electricity markets using a regimeswitching model with time-varying parameters. Energy Economics 2006;28;62-80.

Park H, Mjelde JW, Bessler DA. Price dynamics among U.S. electricity spot markets. Energy Economics 2006;28;81-101.

Perrot-Voisard D, Zachmann G. HHI, an irrelevant market indicator without a relevant market, Larsen Working Paper 21, March 2009.

Pelagatti MM. Bosco B, Parisio L, Baldi F. A robust multivariate long run analysis of European Electricity Prices, FEEM Working Paper 1622007.

Robinson T. The convergence of electricity prices in Europe. Applied Economic Letters $2007 ; 14 ; 473-476$.

Zachman G. Convergence of electricity wholesale prices in Europe?, Deutsches Institut für Wirtschaftsforschung, Berlin, 2005.

Zachman G. Electricity wholesale prices in Europe: Convergence? Energy Economics 2008;30;1659-1671. 
Appendix A. Descriptive statistics

\begin{tabular}{|c|c|c|c|c|c|c|c|c|c|}
\hline & \multirow[b]{2}{*}{ Hour } & \multicolumn{4}{|c|}{ Own price } & \multicolumn{4}{|c|}{ MIX } \\
\hline & & Mean & Max & Min & StDev & Mean & Max & Min & StDev \\
\hline \multirow[t]{24}{*}{ APX } & 1 & 40.80 & 200.97 & 8.01 & 17.99 & 40.56 & 80.24 & 8.01 & 16.97 \\
\hline & 2 & 35.51 & 95.57 & 4.00 & 15.85 & 35.45 & 71.67 & 5.00 & 15.68 \\
\hline & 3 & 31.62 & 85.12 & 0.88 & 14.85 & 31.64 & 68.50 & 2.00 & 14.71 \\
\hline & 4 & 27.50 & 79.93 & 1.09 & 13.90 & 27.45 & 63.37 & 1.09 & 13.83 \\
\hline & 5 & 26.25 & 75.57 & 1.00 & 14.13 & 26.26 & 64.17 & 0.59 & 14.00 \\
\hline & 6 & 32.14 & 75.00 & 1.00 & 15.50 & 32.11 & 70.00 & 1.40 & 15.39 \\
\hline & 7 & 39.33 & 90.00 & 0.50 & 20.91 & 39.30 & 90.00 & 0.07 & 20.85 \\
\hline & 8 & 54.43 & 148.77 & 1.00 & 28.97 & 54.54 & 148.77 & 1.00 & 29.11 \\
\hline & 9 & 62.10 & 227.13 & 7.31 & 31.44 & 62.08 & 227.13 & 7.31 & 31.55 \\
\hline & 10 & 70.71 & 400.00 & 6.31 & 38.68 & 70.30 & 400.00 & 6.31 & 38.65 \\
\hline & 11 & 75.63 & 800.00 & 7.81 & 47.26 & 74.96 & 800.00 & 7.81 & 47.12 \\
\hline & 12 & 82.04 & 950.00 & 9.31 & 53.97 & 80.98 & 950.00 & 9.31 & 52.91 \\
\hline & 13 & 72.09 & 350.00 & 21.70 & 33.17 & 71.43 & 350.00 & 21.70 & 32.31 \\
\hline & 14 & 69.17 & 520.01 & 14.01 & 35.55 & 68.52 & 520.01 & 14.01 & 34.82 \\
\hline & 15 & 66.12 & 950.00 & 9.18 & 45.01 & 65.72 & 950.00 & 9.18 & 44.57 \\
\hline & 16 & 61.11 & 950.00 & 9.17 & 43.68 & 60.59 & 950.00 & 9.17 & 43.12 \\
\hline & 17 & 60.37 & 950.00 & 5.98 & 43.85 & 60.18 & 950.00 & 5.98 & 43.91 \\
\hline & 18 & 70.49 & 850.00 & 9.10 & 60.97 & 70.19 & 850.00 & 9.10 & 59.93 \\
\hline & 19 & 71.55 & 476.00 & 19.91 & 47.41 & 71.45 & 519.93 & 19.30 & 47.82 \\
\hline & 20 & 66.03 & 300.00 & 18.94 & 31.71 & 65.78 & 300.00 & 18.94 & 31.43 \\
\hline & 21 & 60.65 & 139.00 & 20.00 & 24.24 & 60.61 & 140.30 & 19.89 & 24.48 \\
\hline & 22 & 53.08 & 115.72 & 20.97 & 20.42 & 52.99 & 115.72 & 20.97 & 20.52 \\
\hline & 23 & 51.09 & 125.00 & 19.90 & 19.44 & 51.11 & 125.00 & 19.90 & 19.43 \\
\hline & 24 & 46.36 & 120.00 & 16.30 & 18.67 & 46.28 & 120.00 & 16.30 & 18.69 \\
\hline \multirow[t]{24}{*}{ BELPEX } & 1 & 40.63 & 95.90 & 8.01 & 18.55 & 40.66 & 95.90 & 8.01 & 18.55 \\
\hline & 2 & 35.69 & 88.10 & 3.20 & 17.22 & 35.73 & 88.10 & 5.00 & 17.23 \\
\hline & 3 & 31.67 & 71.91 & 2.35 & 16.02 & 31.66 & 71.92 & 2.35 & 16.05 \\
\hline & 4 & 26.59 & 63.94 & 1.09 & 14.70 & 26.59 & 65.00 & 1.09 & 14.77 \\
\hline & 5 & 24.57 & 64.17 & 0.96 & 14.79 & 24.56 & 64.17 & 0.96 & 14.85 \\
\hline & 6 & 31.05 & 70.03 & 2.60 & 16.48 & 31.02 & 70.03 & 2.60 & 16.50 \\
\hline & 7 & 38.46 & 100.01 & 0.07 & 22.32 & 38.38 & 100.01 & 0.07 & 22.32 \\
\hline & 8 & 54.52 & 179.32 & 1.00 & 31.25 & 54.43 & 179.32 & 1.00 & 31.22 \\
\hline & 9 & 62.05 & 227.13 & 7.31 & 33.65 & 61.84 & 227.13 & 7.31 & 33.48 \\
\hline & 10 & 70.21 & 500.00 & 6.31 & 44.26 & 70.04 & 500.00 & 6.31 & 44.21 \\
\hline & 11 & 73.96 & 800.00 & 7.17 & 52.79 & 73.90 & 800.00 & 7.81 & 52.74 \\
\hline & 12 & 78.39 & 950.00 & 8.99 & 55.67 & 78.37 & 950.00 & 9.31 & 55.61 \\
\hline & 13 & 70.94 & 350.14 & 13.98 & 34.82 & 70.92 & 350.14 & 19.04 & 34.75 \\
\hline & 14 & 67.36 & 520.01 & 4.95 & 35.82 & 67.41 & 520.01 & 14.01 & 35.88 \\
\hline & 15 & 64.97 & 950.00 & 8.03 & 45.48 & 64.94 & 950.00 & 9.18 & 45.41 \\
\hline & 16 & 60.34 & 950.00 & 6.51 & 44.16 & 60.33 & 950.00 & 9.17 & 44.17 \\
\hline & 17 & 60.19 & 950.00 & 5.98 & 47.63 & 60.10 & 950.00 & 5.98 & 47.66 \\
\hline & 18 & 69.30 & 850.00 & 9.10 & 64.16 & 69.10 & 850.00 & 9.10 & 64.05 \\
\hline & 19 & 74.97 & $1,762.54$ & 6.90 & 89.79 & 74.94 & $1,762.54$ & 13.03 & 89.75 \\
\hline & 20 & 68.10 & $1,066.82$ & 10.41 & 52.32 & 68.11 & $1,066.82$ & 14.10 & 52.33 \\
\hline & 21 & 64.29 & $2,500.00$ & 5.53 & 94.28 & 64.34 & $2,500.00$ & 13.10 & 94.31 \\
\hline & 22 & 54.44 & 300.03 & 8.36 & 25.03 & 54.41 & 300.03 & 13.09 & 24.95 \\
\hline & 23 & 54.12 & 179.30 & 18.92 & 22.33 & 54.20 & 179.30 & 18.92 & 22.39 \\
\hline & 24 & 48.30 & 210.10 & 16.09 & 21.23 & 48.34 & 210.10 & 16.09 & 21.22 \\
\hline
\end{tabular}




\begin{tabular}{|c|c|c|c|c|c|c|c|c|c|}
\hline & \multirow[b]{2}{*}{ Hour } & \multicolumn{4}{|c|}{ Own price } & \multicolumn{4}{|c|}{ MIX } \\
\hline & & Mean & Max & Min & StDev & Mean & Max & Min & StDev \\
\hline \multirow[t]{24}{*}{ EEX } & 1 & 37.69 & 76.02 & 1.64 & 16.24 & 38.17 & 75.01 & 8.72 & 15.91 \\
\hline & 2 & 32.71 & 71.07 & 0.62 & 15.24 & 33.46 & 70.97 & 0.55 & 14.83 \\
\hline & 3 & 29.28 & 67.93 & 0.25 & 14.37 & 30.20 & 68.50 & 1.00 & 13.58 \\
\hline & 4 & 26.52 & 69.52 & 0.05 & 13.73 & 27.63 & 71.89 & 1.00 & 12.85 \\
\hline & 5 & 27.02 & 69.92 & 0.10 & 13.99 & 27.56 & 70.71 & 1.00 & 13.31 \\
\hline & 6 & 32.81 & 70.51 & 0.02 & 15.70 & 32.69 & 69.75 & 1.00 & 15.04 \\
\hline & 7 & 38.52 & 104.93 & 2.16 & 22.27 & 38.12 & 93.21 & 0.60 & 21.03 \\
\hline & 8 & 54.48 & 301.01 & 0.07 & 32.61 & 53.59 & 149.48 & 1.00 & 29.95 \\
\hline & 9 & 60.26 & 437.26 & 0.33 & 34.80 & 58.95 & 192.01 & 6.00 & 30.50 \\
\hline & 10 & 64.75 & 249.92 & 5.46 & 33.43 & 64.68 & 186.41 & 6.31 & 32.48 \\
\hline & 11 & 68.47 & 240.71 & 0.50 & 34.85 & 68.17 & 200.36 & 7.81 & 33.64 \\
\hline & 12 & 75.59 & 387.11 & 5.56 & 41.87 & 72.88 & 200.00 & 9.31 & 35.80 \\
\hline & 13 & 67.00 & 216.01 & 6.96 & 30.83 & 66.12 & 168.05 & 19.72 & 29.57 \\
\hline & 14 & 63.01 & 250.22 & 2.65 & 30.49 & 62.53 & 147.54 & 14.01 & 28.67 \\
\hline & 15 & 59.40 & 188.48 & 0.07 & 30.30 & 59.27 & 156.02 & 9.18 & 29.16 \\
\hline & 16 & 55.46 & 195.00 & 0.12 & 28.03 & 56.12 & 143.41 & 9.93 & 28.02 \\
\hline & 17 & 54.60 & 250.04 & 3.86 & 28.02 & 55.14 & 195.42 & 8.17 & 27.79 \\
\hline & 18 & 62.03 & 821.90 & 10.95 & 49.25 & 61.55 & 769.47 & 9.18 & 43.68 \\
\hline & 19 & 65.54 & 701.01 & 15.95 & 44.08 & 63.94 & 378.72 & 16.40 & 35.49 \\
\hline & 20 & 61.38 & 299.09 & 17.97 & 31.33 & 61.20 & 196.59 & 15.87 & 29.08 \\
\hline & 21 & 56.18 & 194.62 & 15.07 & 25.38 & 56.32 & 139.00 & 19.71 & 24.92 \\
\hline & 22 & 49.08 & 118.93 & 13.48 & 20.69 & 49.50 & 116.84 & 20.06 & 20.55 \\
\hline & 23 & 47.28 & 94.82 & 14.65 & 18.83 & 47.69 & 91.25 & 20.23 & 18.64 \\
\hline & 24 & 38.78 & 80.98 & 1.61 & 16.53 & 39.69 & 80.19 & 12.96 & 16.42 \\
\hline \multirow[t]{24}{*}{ EXAA } & 1 & 37.48 & 81.00 & 6.83 & 15.25 & 37.90 & 74.10 & 11.12 & 15.18 \\
\hline & 2 & 32.21 & 68.53 & 0.55 & 14.18 & 32.69 & 70.32 & 0.62 & 14.21 \\
\hline & 3 & 28.59 & 65.64 & 0.01 & 13.40 & 29.31 & 65.00 & 1.52 & 13.22 \\
\hline & 4 & 26.11 & 63.27 & 0.01 & 12.78 & 26.69 & 63.47 & 0.06 & 12.73 \\
\hline & 5 & 26.50 & 62.95 & 0.01 & 13.13 & 26.76 & 63.00 & 1.00 & 12.97 \\
\hline & 6 & 31.74 & 71.48 & 0.01 & 15.14 & 32.04 & 70.00 & 0.87 & 14.95 \\
\hline & 7 & 37.91 & 97.37 & 0.01 & 21.33 & 38.54 & 93.83 & 0.14 & 20.72 \\
\hline & 8 & 54.57 & 150.00 & 0.01 & 30.68 & 54.81 & 153.78 & 0.75 & 30.14 \\
\hline & 9 & 60.39 & 192.01 & 0.01 & 31.17 & 60.25 & 192.80 & 4.01 & 31.08 \\
\hline & 10 & 65.41 & 200.51 & 11.00 & 32.14 & 65.49 & 200.00 & 8.68 & 32.83 \\
\hline & 11 & 69.17 & 200.36 & 11.67 & 33.35 & 69.18 & 204.89 & 7.81 & 34.01 \\
\hline & 12 & 75.59 & 248.27 & 0.07 & 37.48 & 75.30 & 226.32 & 5.56 & 37.13 \\
\hline & 13 & 67.95 & 183.33 & 20.60 & 30.82 & 67.55 & 173.30 & 19.72 & 30.33 \\
\hline & 14 & 63.79 & 170.00 & 17.00 & 29.78 & 63.77 & 172.28 & 17.12 & 29.58 \\
\hline & 15 & 60.01 & 153.60 & 3.51 & 29.06 & 60.25 & 164.04 & 11.16 & 29.28 \\
\hline & 16 & 56.73 & 156.27 & 11.27 & 27.71 & 56.83 & 159.08 & 9.91 & 27.64 \\
\hline & 17 & 57.14 & 180.02 & 9.83 & 29.16 & 57.12 & 197.87 & 3.86 & 29.27 \\
\hline & 18 & 65.90 & 517.55 & 12.68 & 48.76 & 64.68 & 596.94 & 11.58 & 46.30 \\
\hline & 19 & 69.31 & 519.93 & 17.60 & 47.68 & 68.71 & 476.00 & 18.54 & 46.94 \\
\hline & 20 & 63.74 & 302.37 & 20.00 & 32.42 & 63.37 & 210.00 & 19.37 & 31.01 \\
\hline & 21 & 57.38 & 137.15 & 20.31 & 24.94 & 57.15 & 140.02 & 15.07 & 24.86 \\
\hline & 22 & 50.16 & 112.59 & 9.99 & 20.44 & 50.11 & 114.00 & 13.48 & 20.37 \\
\hline & 23 & 47.97 & 94.94 & 1.00 & 18.79 & 47.95 & 95.38 & 19.90 & 18.64 \\
\hline & 24 & 39.48 & 81.21 & 1.00 & 16.49 & 39.82 & 83.22 & 9.15 & 16.37 \\
\hline
\end{tabular}




\begin{tabular}{|c|c|c|c|c|c|c|c|c|c|}
\hline & \multirow[b]{2}{*}{ Hour } & \multicolumn{4}{|c|}{ Own price } & \multicolumn{4}{|c|}{ MIX } \\
\hline & & Mean & Max & Min & StDev & Mean & Max & Min & StDev \\
\hline \multirow[t]{24}{*}{ IPEX } & 1 & 53.86 & 110.00 & 22.54 & 14.83 & 47.61 & 85.00 & 21.68 & 15.00 \\
\hline & 2 & 45.93 & 92.65 & 22.00 & 15.21 & 41.61 & 79.91 & 19.49 & 14.28 \\
\hline & 3 & 40.22 & 84.76 & 21.44 & 14.27 & 37.09 & 71.91 & 18.35 & 12.91 \\
\hline & 4 & 37.11 & 75.89 & 21.44 & 12.87 & 34.36 & 70.00 & 16.94 & 11.64 \\
\hline & 5 & 36.61 & 73.63 & 21.52 & 12.33 & 33.84 & 69.92 & 18.51 & 11.19 \\
\hline & 6 & 41.47 & 75.02 & 22.00 & 13.45 & 37.42 & 70.51 & 18.52 & 13.08 \\
\hline & 7 & 54.10 & 93.83 & 22.04 & 15.74 & 45.62 & 89.25 & 19.03 & 17.27 \\
\hline & 8 & 70.59 & 137.60 & 22.05 & 22.05 & 59.83 & 139.48 & 20.07 & 25.88 \\
\hline & 9 & 88.97 & 176.94 & 21.63 & 23.68 & 66.96 & 180.42 & 18.27 & 28.53 \\
\hline & 10 & 111.11 & 215.55 & 26.63 & 31.23 & 74.17 & 200.00 & 26.61 & 32.59 \\
\hline & 11 & 118.12 & 209.96 & 39.17 & 34.09 & 78.40 & 200.36 & 27.05 & 33.60 \\
\hline & 12 & 113.03 & 211.99 & 46.61 & 33.98 & 82.60 & 200.00 & 28.76 & 35.05 \\
\hline & 13 & 89.75 & 194.83 & 43.30 & 23.89 & 73.29 & 171.03 & 29.34 & 26.95 \\
\hline & 14 & 84.53 & 179.12 & 23.64 & 23.69 & 70.47 & 165.09 & 23.67 & 25.57 \\
\hline & 15 & 89.54 & 197.41 & 24.67 & 29.18 & 68.83 & 164.04 & 26.05 & 27.17 \\
\hline & 16 & 94.02 & 209.80 & 23.66 & 32.72 & 65.15 & 159.08 & 20.06 & 25.76 \\
\hline & 17 & 102.11 & 198.51 & 23.61 & 37.57 & 65.69 & 205.80 & 19.93 & 27.79 \\
\hline & 18 & 104.53 & 239.52 & 23.32 & 41.57 & 72.14 & 301.15 & 22.14 & 37.48 \\
\hline & 19 & 103.64 & 242.42 & 22.00 & 39.28 & 74.87 & 301.50 & 21.40 & 38.10 \\
\hline & 20 & 96.60 & 190.01 & 41.90 & 26.48 & 72.05 & 180.02 & 27.15 & 30.46 \\
\hline & 21 & 93.64 & 162.63 & 49.35 & 20.37 & 68.29 & 142.73 & 29.15 & 25.01 \\
\hline & 22 & 83.82 & 150.14 & 46.27 & 17.94 & 64.50 & 118.04 & 29.48 & 20.07 \\
\hline & 23 & 69.24 & 116.58 & 43.90 & 15.13 & 59.01 & 110.03 & 29.61 & 17.91 \\
\hline & 24 & 60.63 & 110.45 & 22.00 & 13.60 & 52.37 & 103.78 & 21.52 & 16.68 \\
\hline \multirow[t]{24}{*}{ NordPool } & 1 & 32.82 & 67.16 & 3.92 & 13.95 & 36.77 & 70.05 & 6.98 & 13.78 \\
\hline & 2 & 31.37 & 65.94 & 3.73 & 13.95 & 33.51 & 66.14 & 2.76 & 13.42 \\
\hline & 3 & 30.21 & 64.93 & 3.07 & 13.88 & 31.33 & 65.00 & 2.06 & 13.09 \\
\hline & 4 & 29.51 & 63.96 & 2.87 & 13.86 & 29.88 & 64.00 & 2.07 & 13.08 \\
\hline & 5 & 29.74 & 65.12 & 2.48 & 14.06 & 29.83 & 62.92 & 1.96 & 13.27 \\
\hline & 6 & 31.42 & 67.83 & 2.35 & 14.36 & 32.51 & 67.95 & 1.05 & 13.63 \\
\hline & 7 & 33.95 & 75.74 & 2.04 & 14.68 & 36.71 & 80.95 & 3.49 & 15.66 \\
\hline & 8 & 37.15 & 78.33 & 2.71 & 15.01 & 39.89 & 79.06 & 1.13 & 15.46 \\
\hline & 9 & 39.02 & 80.18 & 4.59 & 15.16 & 43.45 & 99.56 & 9.92 & 15.96 \\
\hline & 10 & 39.26 & 76.26 & 7.32 & 14.71 & 45.82 & 88.60 & 14.06 & 16.64 \\
\hline & 11 & 39.41 & 76.22 & 9.15 & 14.48 & 47.13 & 89.55 & 17.08 & 17.63 \\
\hline & 12 & 39.10 & 76.24 & 11.14 & 14.33 & 48.00 & 91.00 & 16.04 & 17.93 \\
\hline & 13 & 38.52 & 74.79 & 10.85 & 14.29 & 48.04 & 93.38 & 19.04 & 18.20 \\
\hline & 14 & 37.93 & 74.52 & 9.22 & 14.34 & 46.89 & 91.31 & 17.00 & 18.05 \\
\hline & 15 & 37.42 & 74.14 & 7.45 & 14.37 & 44.95 & 88.33 & 14.97 & 16.76 \\
\hline & 16 & 37.02 & 74.03 & 7.31 & 14.35 & 43.76 & 87.41 & 15.02 & 16.39 \\
\hline & 17 & 37.14 & 73.64 & 7.35 & 14.48 & 43.63 & 100.00 & 14.98 & 16.15 \\
\hline & 18 & 38.19 & 99.91 & 9.80 & 14.82 & 44.77 & 80.87 & 15.95 & 16.40 \\
\hline & 19 & 38.17 & 74.12 & 11.09 & 14.33 & 46.47 & 90.00 & 17.90 & 17.50 \\
\hline & 20 & 37.63 & 77.94 & 10.61 & 14.23 & 47.26 & 96.75 & 16.32 & 17.92 \\
\hline & 21 & 36.95 & 76.16 & 8.73 & 14.16 & 46.49 & 95.36 & 17.86 & 18.29 \\
\hline & 22 & 36.57 & 73.90 & 8.40 & 13.91 & 43.73 & 87.00 & 15.47 & 15.88 \\
\hline & 23 & 35.88 & 72.08 & 8.60 & 13.71 & 43.12 & 76.47 & 15.17 & 15.58 \\
\hline & 24 & 33.66 & 68.70 & 5.91 & 13.84 & 38.59 & 71.42 & 16.09 & 14.52 \\
\hline
\end{tabular}




\begin{tabular}{|c|c|c|c|c|c|c|c|c|c|}
\hline & \multirow[b]{2}{*}{ Hour } & \multicolumn{4}{|c|}{ Own price } & \multicolumn{4}{|c|}{ MIX } \\
\hline & & Mean & Max & Min & StDev & Mean & Max & Min & StDev \\
\hline \multirow[t]{24}{*}{ Omel } & 1 & 48.13 & 90.00 & 18.50 & 15.57 & 45.83 & 87.00 & 22.47 & 15.22 \\
\hline & 2 & 43.63 & 87.69 & 6.50 & 14.76 & 41.24 & 83.33 & 16.10 & 14.81 \\
\hline & 3 & 39.67 & 80.01 & 1.00 & 14.13 & 37.53 & 77.21 & 13.99 & 13.59 \\
\hline & 4 & 38.16 & 70.00 & 5.00 & 13.68 & 35.61 & 75.89 & 11.78 & 13.10 \\
\hline & 5 & 36.81 & 66.01 & 5.00 & 13.71 & 34.46 & 73.26 & 9.17 & 12.78 \\
\hline & 6 & 37.51 & 66.32 & 5.00 & 13.87 & 36.17 & 71.16 & 7.15 & 13.50 \\
\hline & 7 & 41.28 & 76.30 & 6.50 & 14.76 & 40.78 & 75.96 & 6.00 & 15.05 \\
\hline & 8 & 46.18 & 83.90 & 5.00 & 16.72 & 44.91 & 100.00 & 4.46 & 16.59 \\
\hline & 9 & 49.99 & 92.82 & 5.00 & 17.62 & 48.84 & 103.00 & 8.18 & 17.75 \\
\hline & 10 & 53.42 & 95.68 & 10.00 & 17.71 & 52.13 & 101.96 & 11.41 & 18.05 \\
\hline & 11 & 57.23 & 99.05 & 18.67 & 17.80 & 55.18 & 102.32 & 18.27 & 18.49 \\
\hline & 12 & 58.01 & 99.13 & 18.67 & 17.29 & 56.48 & 109.35 & 22.33 & 18.48 \\
\hline & 13 & 58.50 & 99.16 & 19.00 & 17.22 & 56.99 & 106.31 & 23.21 & 18.55 \\
\hline & 14 & 57.31 & 96.62 & 20.10 & 16.89 & 55.56 & 103.82 & 21.43 & 18.36 \\
\hline & 15 & 52.85 & 89.92 & 20.10 & 15.93 & 51.69 & 94.42 & 19.60 & 16.91 \\
\hline & 16 & 51.21 & 91.00 & 20.00 & 15.80 & 50.01 & 90.48 & 17.20 & 16.60 \\
\hline & 17 & 51.13 & 90.00 & 16.00 & 16.26 & 49.36 & 97.98 & 13.44 & 16.53 \\
\hline & 18 & 52.80 & 90.77 & 18.67 & 17.04 & 51.08 & 104.93 & 17.90 & 17.51 \\
\hline & 19 & 56.16 & 129.99 & 20.00 & 19.03 & 54.34 & 112.91 & 21.61 & 19.95 \\
\hline & 20 & 58.11 & 130.00 & 23.24 & 20.01 & 56.47 & 137.70 & 20.00 & 21.53 \\
\hline & 21 & 59.47 & 103.09 & 24.00 & 19.89 & 57.75 & 120.81 & 23.02 & 21.31 \\
\hline & 22 & 60.82 & 100.00 & 25.64 & 18.32 & 58.99 & 115.03 & 25.29 & 21.03 \\
\hline & 23 & 55.91 & 95.00 & 23.50 & 17.16 & 54.40 & 96.07 & 23.47 & 18.00 \\
\hline & 24 & 51.15 & 93.36 & 0.00 & 17.16 & 49.52 & 89.93 & 0.00 & 16.75 \\
\hline \multirow[t]{24}{*}{ POLPX } & 1 & 39.85 & 66.92 & 19.76 & 13.50 & 37.28 & 66.46 & 15.40 & 12.86 \\
\hline & 2 & 44.06 & 77.75 & 26.96 & 15.41 & 32.41 & 65.05 & 10.33 & 11.40 \\
\hline & 3 & 44.59 & 87.68 & 24.96 & 15.98 & 29.86 & 64.12 & 9.07 & 10.26 \\
\hline & 4 & 51.66 & 145.44 & 24.96 & 24.86 & 28.42 & 62.50 & 6.40 & 9.30 \\
\hline & 5 & 55.22 & 166.10 & 23.58 & 29.54 & 27.33 & 62.50 & 9.04 & 8.53 \\
\hline & 6 & 50.70 & 166.87 & 18.76 & 23.21 & 30.32 & 63.56 & 9.04 & 10.53 \\
\hline & 7 & 49.63 & 166.87 & 18.76 & 23.07 & 37.84 & 76.26 & 8.52 & 14.32 \\
\hline & 8 & 47.12 & 147.19 & 18.25 & 17.97 & 40.17 & 89.99 & 7.93 & 15.02 \\
\hline & 9 & 45.88 & 142.17 & 18.76 & 18.20 & 44.09 & 85.33 & 11.63 & 15.91 \\
\hline & 10 & 47.45 & 142.17 & 18.76 & 19.48 & 47.54 & 112.51 & 11.41 & 18.15 \\
\hline & 11 & 49.01 & 142.17 & 19.54 & 20.73 & 49.08 & 125.61 & 18.51 & 19.70 \\
\hline & 12 & 49.31 & 142.17 & 18.32 & 21.37 & 50.22 & 132.65 & 15.28 & 21.20 \\
\hline & 13 & 49.18 & 142.17 & 18.27 & 21.32 & 50.26 & 125.09 & 15.22 & 21.79 \\
\hline & 14 & 48.23 & 142.17 & 18.27 & 20.38 & 50.05 & 122.65 & 15.21 & 21.08 \\
\hline & 15 & 47.04 & 142.17 & 18.27 & 19.55 & 47.75 & 115.05 & 15.10 & 19.21 \\
\hline & 16 & 43.29 & 90.52 & 18.24 & 16.06 & 46.36 & 107.23 & 14.73 & 18.01 \\
\hline & 17 & 38.68 & 83.16 & 17.98 & 14.39 & 47.02 & 102.76 & 17.69 & 17.88 \\
\hline & 18 & 37.17 & 72.69 & 17.98 & 13.52 & 49.19 & 177.75 & 20.16 & 22.40 \\
\hline & 19 & 28.29 & 64.67 & 15.84 & 8.02 & 50.98 & 177.82 & 18.54 & 23.27 \\
\hline & 20 & 26.12 & 53.92 & 17.98 & 6.68 & 55.04 & 160.70 & 22.30 & 27.89 \\
\hline & 21 & 26.72 & 54.46 & 2.11 & 7.66 & 52.27 & 157.22 & 24.00 & 24.06 \\
\hline & 22 & 27.36 & 59.09 & 18.05 & 8.09 & 45.61 & 93.17 & 23.51 & 16.54 \\
\hline & 23 & 30.00 & 63.44 & 18.21 & 9.24 & 45.07 & 79.85 & 23.72 & 15.74 \\
\hline & 24 & 35.06 & 65.78 & 18.57 & 11.29 & 40.57 & 75.00 & 20.16 & 14.38 \\
\hline
\end{tabular}




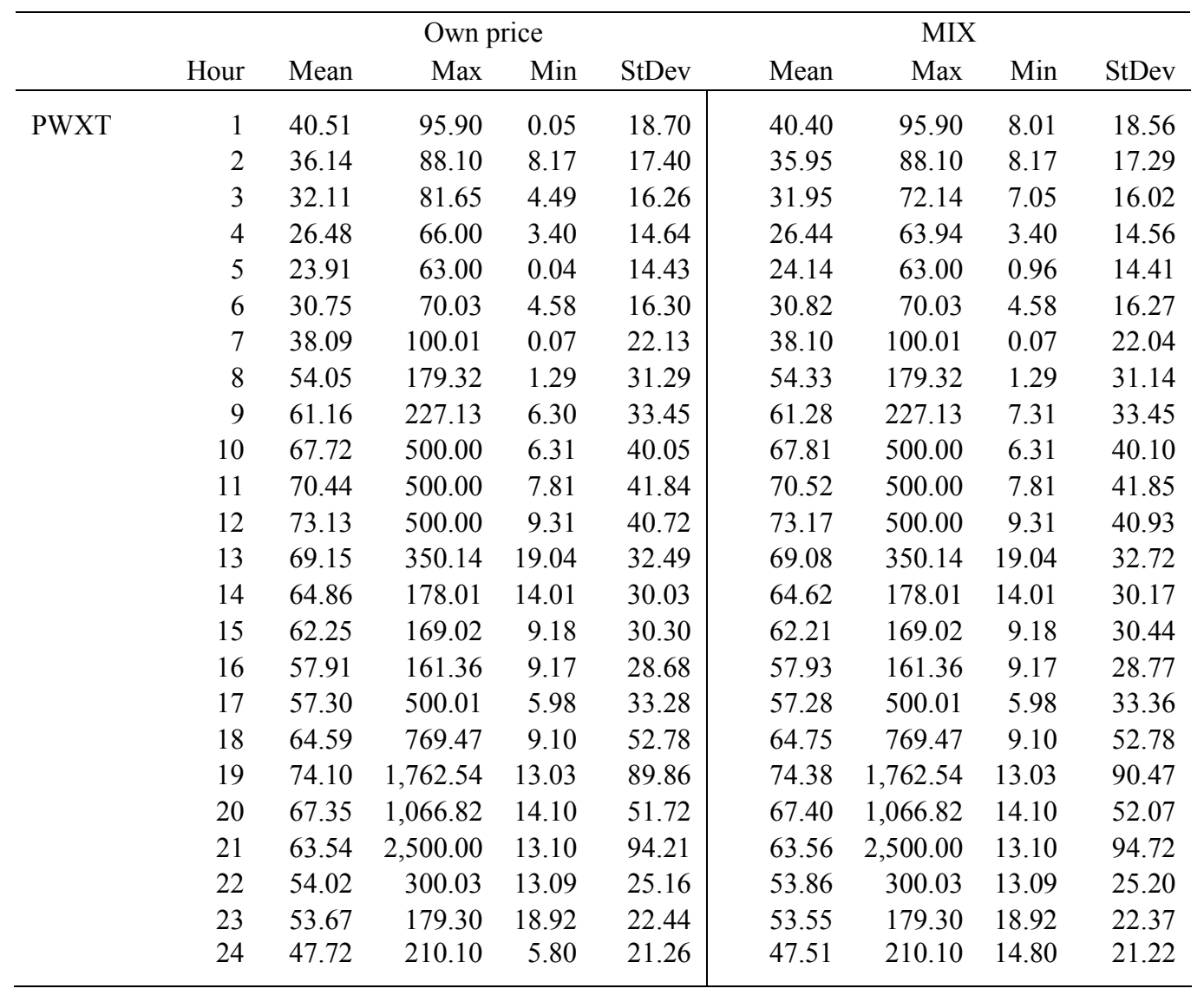




\section{Appendix B. Full results convergence test with MIX prices}

Table B.1 Estimation results APX as function of MIX

\begin{tabular}{|c|c|c|c|c|c|c|c|c|c|c|}
\hline & \multicolumn{2}{|c|}{ MIX } & \multicolumn{2}{|c|}{ Constant } & \multicolumn{3}{|c|}{ Wald-test $^{1}$} & \multicolumn{2}{|c|}{ Difference } & \multirow[b]{2}{*}{ Conclusion } \\
\hline & Coeff & St. error & Coeff & St. error & $\mathrm{R}^{2}$ & Wald & Prob & Effect $^{2}$ & $\%$ mean & \\
\hline 1 & 1.02 & 0.01 & -0.73 & 0.45 & 0.93 & 3.60 & 0.03 & 0.23 & 0.57 & Rejected \\
\hline 2 & 1.01 & 0.00 & -0.17 & 0.14 & 0.99 & 2.16 & 0.12 & 0.06 & 0.17 & $\mathrm{OK}$ \\
\hline 3 & 1.00 & 0.00 & -0.20 & 0.13 & 0.99 & 1.13 & 0.32 & -0.05 & -0.16 & $\mathrm{OK}$ \\
\hline 4 & 1.00 & 0.00 & 0.02 & 0.12 & 0.99 & 0.18 & 0.83 & 0.03 & 0.11 & OK \\
\hline 5 & 1.00 & 0.00 & -0.13 & 0.11 & 0.99 & 0.66 & 0.52 & -0.03 & -0.10 & $\mathrm{OK}$ \\
\hline 6 & 1.00 & 0.00 & -0.11 & 0.12 & 0.99 & 0.56 & 0.57 & 0.01 & 0.02 & $\mathrm{OK}$ \\
\hline 7 & 1.00 & 0.00 & -0.02 & 0.09 & 1.00 & 0.32 & 0.73 & 0.03 & 0.07 & $\mathrm{OK}$ \\
\hline 8 & 0.99 & 0.00 & 0.21 & 0.10 & 1.00 & 9.58 & 0.00 & -0.11 & -0.20 & Rejected \\
\hline 9 & 1.00 & 0.00 & 0.33 & 0.14 & 1.00 & 2.95 & 0.05 & 0.03 & 0.04 & $\mathrm{OK}$ \\
\hline 10 & 1.00 & 0.00 & 0.54 & 0.21 & 0.99 & 8.15 & 0.00 & 0.40 & 0.57 & Rejected \\
\hline 11 & 1.00 & 0.00 & 0.90 & 0.36 & 0.99 & 6.33 & 0.00 & 0.67 & 0.89 & Rejected \\
\hline 12 & 1.00 & 0.01 & 1.36 & 0.79 & 0.95 & 3.10 & 0.05 & 1.05 & 1.30 & Rejected \\
\hline 13 & 1.00 & 0.01 & 0.81 & 0.70 & 0.94 & 2.67 & 0.07 & 0.66 & 0.93 & $\mathrm{OK}$ \\
\hline 14 & 1.00 & 0.01 & 0.87 & 0.63 & 0.95 & 2.75 & 0.06 & 0.66 & 0.96 & OK \\
\hline 15 & 1.00 & 0.01 & 0.52 & 0.45 & 0.98 & 1.25 & 0.29 & 0.39 & 0.60 & $\mathrm{OK}$ \\
\hline 16 & 1.00 & 0.01 & 0.43 & 0.42 & 0.98 & 2.34 & 0.10 & 0.52 & 0.86 & $\mathrm{OK}$ \\
\hline 17 & 1.00 & 0.00 & 0.38 & 0.15 & 1.00 & 3.36 & 0.04 & 0.19 & 0.32 & Rejected \\
\hline 18 & 1.01 & 0.00 & -0.74 & 0.25 & 0.99 & 15.77 & 0.00 & 0.29 & 0.42 & Rejected \\
\hline 19 & 0.99 & 0.00 & 0.97 & 0.27 & 0.99 & 7.77 & 0.00 & 0.10 & 0.14 & Rejected \\
\hline 20 & 1.00 & 0.00 & 0.20 & 0.35 & 0.98 & 1.45 & 0.23 & 0.25 & 0.39 & $\mathrm{OK}$ \\
\hline 21 & 0.99 & 0.00 & 0.89 & 0.22 & 0.99 & 8.66 & 0.00 & 0.04 & 0.07 & Rejected \\
\hline 22 & 0.99 & 0.00 & 0.51 & 0.16 & 0.99 & 4.99 & 0.01 & 0.09 & 0.17 & Rejected \\
\hline 23 & 1.00 & 0.00 & 0.09 & 0.14 & 1.00 & 0.40 & 0.67 & -0.02 & -0.03 & $\mathrm{OK}$ \\
\hline 24 & 1.00 & 0.00 & 0.30 & 0.14 & 0.99 & 3.48 & 0.03 & 0.11 & 0.24 & Rejected \\
\hline
\end{tabular}

1. Wald test is the test that the coefficient for PWXT $=1$ and the constant $=0$.

2. The effect is calculated at the sample mean and given in euro per MWh difference with the sample mean.

Bold coefficients and test-statistics are significant at $5 \%$. 
Table B.2 Estimation results EEX as function of MIX

\begin{tabular}{|c|c|c|c|c|c|c|c|c|c|c|}
\hline & \multicolumn{2}{|c|}{ MIX } & \multicolumn{2}{|c|}{ Constant } & \multicolumn{3}{|c|}{ Wald-test $^{1}$} & \multicolumn{2}{|c|}{ Difference } & \multirow[b]{2}{*}{ Conclusion } \\
\hline & Coeff & St. error & Coeff & St. error & $\mathrm{R}^{2}$ & Wald & Prob & Effect $^{2}$ & $\%$ mean & \\
\hline 1 & 0.99 & 0.01 & -0.22 & 0.36 & 0.95 & 6.23 & 0.00 & -0.48 & -1.25 & Rejected \\
\hline 2 & 1.00 & 0.01 & -0.87 & 0.34 & 0.94 & 19.35 & 0.00 & -0.85 & -2.53 & Rejected \\
\hline 3 & 1.02 & 0.01 & -1.47 & 0.36 & 0.92 & 22.31 & 0.00 & -0.95 & -3.15 & Rejected \\
\hline 4 & 1.01 & 0.01 & -1.42 & 0.39 & 0.90 & 23.63 & 0.00 & -1.12 & -4.06 & Rejected \\
\hline 5 & 1.00 & 0.01 & -0.53 & 0.38 & 0.90 & 6.83 & 0.00 & -0.60 & -2.18 & Rejected \\
\hline 6 & 1.01 & 0.01 & -0.35 & 0.36 & 0.93 & 0.72 & 0.49 & 0.03 & 0.09 & $\mathrm{OK}$ \\
\hline 7 & 1.05 & 0.01 & -2.20 & 0.38 & 0.95 & 18.27 & 0.00 & -0.26 & -0.69 & Rejected \\
\hline 8 & 1.03 & 0.01 & -0.95 & 0.90 & 0.87 & 2.11 & 0.12 & 0.43 & 0.80 & $\mathrm{OK}$ \\
\hline 9 & 0.97 & 0.02 & 3.12 & 1.49 & 0.72 & 2.65 & 0.07 & 1.25 & 2.12 & $\mathrm{OK}$ \\
\hline 10 & 1.00 & 0.01 & -0.04 & 0.66 & 0.94 & 0.00 & 1.00 & -0.01 & -0.02 & $\mathrm{OK}$ \\
\hline 11 & 0.99 & 0.01 & 0.78 & 0.83 & 0.92 & 0.54 & 0.58 & 0.30 & 0.44 & $\mathrm{OK}$ \\
\hline 12 & 0.96 & 0.02 & 5.33 & 1.99 & 0.68 & 5.83 & 0.00 & 2.70 & 3.71 & Rejected \\
\hline 13 & 0.96 & 0.02 & 3.73 & 1.11 & 0.84 & 5.85 & 0.00 & 0.88 & 1.33 & Rejected \\
\hline 14 & 0.99 & 0.01 & 1.33 & 1.01 & 0.86 & 1.06 & 0.35 & 0.48 & 0.76 & $\mathrm{OK}$ \\
\hline 15 & 0.97 & 0.01 & 1.74 & 0.89 & 0.88 & 2.07 & 0.13 & 0.14 & 0.23 & $\mathrm{OK}$ \\
\hline 16 & 0.99 & 0.01 & 0.16 & 0.40 & 0.97 & 9.57 & 0.00 & -0.66 & -1.18 & Rejected \\
\hline 17 & 0.99 & 0.01 & -0.03 & 0.43 & 0.97 & 4.80 & 0.01 & -0.54 & -0.98 & Rejected \\
\hline 18 & 0.99 & 0.02 & 1.13 & 1.51 & 0.77 & 0.29 & 0.75 & 0.48 & 0.77 & $\mathrm{OK}$ \\
\hline 19 & 0.95 & 0.03 & 4.63 & 2.16 & 0.59 & 2.45 & 0.09 & 1.59 & 2.49 & $\mathrm{OK}$ \\
\hline 20 & 1.00 & 0.01 & 0.12 & 1.00 & 0.86 & 0.08 & 0.92 & 0.17 & 0.29 & $\mathrm{OK}$ \\
\hline 21 & 1.00 & 0.01 & -0.28 & 0.41 & 0.97 & 0.41 & 0.66 & -0.14 & -0.24 & $\mathrm{OK}$ \\
\hline 22 & 0.99 & 0.01 & -0.12 & 0.32 & 0.97 & 6.40 & 0.00 & -0.42 & -0.85 & Rejected \\
\hline 23 & 1.00 & 0.01 & -0.26 & 0.31 & 0.97 & 6.69 & 0.00 & -0.41 & -0.85 & Rejected \\
\hline 24 & 0.99 & 0.01 & -0.37 & 0.32 & 0.96 & 29.78 & 0.00 & -0.91 & -2.30 & Rejected \\
\hline
\end{tabular}

1. Wald test is the test that the coefficient for PWXT $=1$ and the constant $=0$.

2. The effect is calculated at the sample mean and given in euro per MWh difference with the sample mean. Bold coefficients and test-statistics are significant at 5\%. 
Table B.3 Estimation results EXAA as function of MIX

\begin{tabular}{|c|c|c|c|c|c|c|c|c|c|c|}
\hline & \multicolumn{2}{|c|}{ MIX } & \multicolumn{2}{|c|}{ Constant } & \multicolumn{3}{|c|}{ Wald-test $^{1}$} & \multicolumn{2}{|c|}{ Difference } & \multirow[b]{2}{*}{ Conclusion } \\
\hline & Coeff & St. error & Coeff & St. error & $\mathrm{R}^{2}$ & Wald & Prob & Effect $^{2}$ & $\%$ mean & \\
\hline 1 & 0.99 & 0.01 & -0.15 & 0.23 & 0.98 & 12.64 & 0.00 & -0.42 & -1.11 & Rejected \\
\hline 2 & 0.98 & 0.01 & 0.09 & 0.22 & 0.97 & 17.57 & 0.00 & -0.46 & -1.39 & Rejected \\
\hline 3 & 0.99 & 0.01 & -0.12 & 0.22 & 0.97 & 19.66 & 0.00 & -0.55 & -1.86 & Rejected \\
\hline 4 & 0.98 & 0.01 & 0.11 & 0.21 & 0.96 & 17.42 & 0.00 & -0.45 & -1.68 & Rejected \\
\hline 5 & 0.99 & 0.01 & 0.03 & 0.19 & 0.97 & 2.54 & 0.08 & -0.16 & -0.60 & $\mathrm{OK}$ \\
\hline 6 & 0.99 & 0.01 & 0.03 & 0.21 & 0.97 & 2.63 & 0.07 & -0.18 & -0.57 & $\mathrm{OK}$ \\
\hline 7 & 1.00 & 0.01 & -0.27 & 0.23 & 0.98 & 0.68 & 0.51 & -0.08 & -0.22 & $\mathrm{OK}$ \\
\hline 8 & 1.00 & 0.00 & -0.02 & 0.28 & 0.99 & 1.15 & 0.32 & 0.17 & 0.32 & $\mathrm{OK}$ \\
\hline 9 & 0.99 & 0.01 & 0.58 & 0.36 & 0.98 & 1.33 & 0.26 & 0.15 & 0.24 & $\mathrm{OK}$ \\
\hline 10 & 0.97 & 0.00 & 1.82 & 0.35 & 0.98 & 19.07 & 0.00 & -0.09 & -0.13 & Rejected \\
\hline 11 & 0.97 & 0.00 & 1.85 & 0.34 & 0.99 & 18.44 & 0.00 & -0.01 & -0.02 & Rejected \\
\hline 12 & 1.00 & 0.01 & 0.46 & 0.48 & 0.98 & 0.97 & 0.38 & 0.28 & 0.37 & $\mathrm{OK}$ \\
\hline 13 & 1.01 & 0.00 & -0.11 & 0.37 & 0.98 & 4.69 & 0.01 & 0.40 & 0.59 & Rejected \\
\hline 14 & 1.00 & 0.00 & 0.02 & 0.30 & 0.99 & 0.01 & 0.99 & 0.02 & 0.03 & $\mathrm{OK}$ \\
\hline 15 & 0.98 & 0.00 & 0.67 & 0.31 & 0.98 & 6.94 & 0.00 & -0.24 & -0.40 & Rejected \\
\hline 16 & 1.00 & 0.00 & 0.19 & 0.28 & 0.99 & 0.90 & 0.41 & -0.10 & -0.17 & $\mathrm{OK}$ \\
\hline 17 & 0.99 & 0.00 & 0.68 & 0.30 & 0.98 & 3.17 & 0.04 & 0.02 & 0.03 & Rejected \\
\hline 18 & 1.03 & 0.01 & -0.90 & 0.61 & 0.96 & 15.42 & 0.00 & 1.23 & 1.90 & Rejected \\
\hline 19 & 1.01 & 0.01 & 0.24 & 0.45 & 0.98 & 3.36 & 0.04 & 0.60 & 0.88 & Rejected \\
\hline 20 & 1.03 & 0.01 & -1.66 & 0.44 & 0.97 & 14.71 & 0.00 & 0.36 & 0.57 & Rejected \\
\hline 21 & 1.00 & 0.00 & 0.46 & 0.28 & 0.99 & 2.63 & 0.07 & 0.23 & 0.41 & $\mathrm{OK}$ \\
\hline 22 & 1.00 & 0.00 & 0.21 & 0.23 & 0.99 & 0.43 & 0.65 & 0.04 & 0.09 & $\mathrm{OK}$ \\
\hline 23 & 1.00 & 0.00 & 0.07 & 0.26 & 0.98 & 0.05 & 0.95 & 0.02 & 0.05 & $\mathrm{OK}$ \\
\hline 24 & 1.00 & 0.01 & -0.19 & 0.24 & 0.98 & 7.37 & 0.00 & -0.34 & -0.85 & Rejected \\
\hline
\end{tabular}

1. Wald test is the test that the coefficient for PWXT $=1$ and the constant $=0$.

2. The effect is calculated at the sample mean and given in euro per MWh difference with the sample mean. Bold coefficients and test-statistics are significant at 5\%. 
Table B.4 Estimation results IPEX as function of MIX

\begin{tabular}{|c|c|c|c|c|c|c|c|c|c|c|}
\hline & \multicolumn{2}{|c|}{ MIX } & \multicolumn{2}{|c|}{ Constant } & \multicolumn{3}{|c|}{ Wald-test $^{1}$} & \multicolumn{2}{|c|}{ Difference } & \multirow[b]{2}{*}{ Conclusion } \\
\hline & Coeff & St. error & Coeff & St. error & $\mathrm{R}^{2}$ & Wald & Prob & Effect $^{2}$ & $\%$ mean & \\
\hline 1 & 0.86 & 0.02 & 13.12 & 0.92 & 0.75 & 289.49 & 0.00 & 6.25 & 13.13 & Rejected \\
\hline 2 & 0.95 & 0.02 & 6.42 & 0.79 & 0.79 & 147.38 & 0.00 & 4.32 & 10.38 & Rejected \\
\hline 3 & 1.00 & 0.02 & 2.99 & 0.67 & 0.82 & 99.57 & 0.00 & 3.12 & 8.42 & Rejected \\
\hline 4 & 1.00 & 0.02 & 2.78 & 0.64 & 0.82 & 90.66 & 0.00 & 2.75 & 7.99 & Rejected \\
\hline 5 & 0.98 & 0.02 & 3.42 & 0.66 & 0.79 & 89.12 & 0.00 & 2.77 & 8.19 & Rejected \\
\hline 6 & 0.91 & 0.02 & 7.30 & 0.69 & 0.79 & 168.47 & 0.00 & 4.05 & 10.82 & Rejected \\
\hline 7 & 0.80 & 0.02 & 17.58 & 0.79 & 0.77 & 540.24 & 0.00 & 8.48 & 18.59 & Rejected \\
\hline 8 & 0.74 & 0.02 & 26.32 & 1.02 & 0.75 & 491.90 & 0.00 & 10.76 & 17.99 & Rejected \\
\hline 9 & 0.62 & 0.02 & 47.21 & 1.48 & 0.56 & 896.44 & 0.00 & 22.02 & 32.89 & Rejected \\
\hline 10 & 0.52 & 0.03 & 72.27 & 2.41 & 0.30 & 856.72 & 0.00 & 36.94 & 49.80 & Rejected \\
\hline 11 & 0.52 & 0.03 & 77.51 & 2.76 & 0.26 & 781.24 & 0.00 & 39.72 & 50.66 & Rejected \\
\hline 12 & 0.58 & 0.03 & 64.74 & 2.57 & 0.36 & 564.71 & 0.00 & 30.43 & 36.83 & Rejected \\
\hline 13 & 0.63 & 0.02 & 43.69 & 1.81 & 0.50 & 477.40 & 0.00 & 16.46 & 22.46 & Rejected \\
\hline 14 & 0.70 & 0.02 & 34.91 & 1.67 & 0.58 & 392.56 & 0.00 & 14.06 & 19.95 & Rejected \\
\hline 15 & 0.67 & 0.03 & 43.46 & 2.30 & 0.39 & 357.13 & 0.00 & 20.71 & 30.08 & Rejected \\
\hline 16 & 0.67 & 0.04 & 50.46 & 2.80 & 0.28 & 427.65 & 0.00 & 28.88 & 44.32 & Rejected \\
\hline 17 & 0.72 & 0.04 & 54.79 & 3.02 & 0.28 & 500.90 & 0.00 & 36.42 & 55.44 & Rejected \\
\hline 18 & 0.78 & 0.03 & 48.26 & 2.37 & 0.49 & 466.81 & 0.00 & 32.39 & 44.89 & Rejected \\
\hline 19 & 0.74 & 0.03 & 48.51 & 2.24 & 0.51 & 448.73 & 0.00 & 28.77 & 38.43 & Rejected \\
\hline 20 & 0.66 & 0.02 & 49.28 & 1.65 & 0.57 & 863.64 & 0.00 & 24.56 & 34.08 & Rejected \\
\hline 21 & 0.60 & 0.02 & 52.71 & 1.49 & 0.54 & $1,425.35$ & 0.00 & 25.34 & 37.11 & Rejected \\
\hline 22 & 0.59 & 0.02 & 45.59 & 1.67 & 0.44 & 890.49 & 0.00 & 19.33 & 29.96 & Rejected \\
\hline 23 & 0.70 & 0.02 & 27.78 & 1.07 & 0.69 & 686.80 & 0.00 & 10.23 & 17.34 & Rejected \\
\hline 24 & 0.67 & 0.02 & 25.35 & 0.94 & 0.68 & 596.89 & 0.00 & 8.22 & 15.69 & Rejected \\
\hline
\end{tabular}

1. Wald test is the test that the coefficient for PWXT $=1$ and the constant $=0$.

2. The effect is calculated at the sample mean and given in euro per MWh difference with the sample mean. Bold coefficients and test-statistics are significant at 5\%. 
Table B.5 Estimation results NordPool as function of MIX

\begin{tabular}{|c|c|c|c|c|c|c|c|c|c|c|}
\hline & \multicolumn{2}{|c|}{ MIX } & \multicolumn{2}{|c|}{ Constant } & \multicolumn{3}{|c|}{ Wald-test $^{1}$} & \multicolumn{2}{|c|}{ Difference } & \multirow[b]{2}{*}{ Conclusion } \\
\hline & Coeff & St. error & Coeff & St. error & $\mathrm{R}^{2}$ & Wald & Prob & Effect $^{2}$ & $\%$ mean & \\
\hline 1 & 0.88 & 0.02 & 0.62 & 0.74 & 0.75 & 137.84 & 0.00 & -3.95 & -10.74 & Rejected \\
\hline 2 & 0.95 & 0.02 & -0.49 & 0.56 & 0.84 & 57.42 & 0.00 & -2.14 & -6.39 & Rejected \\
\hline 3 & 0.99 & 0.01 & -0.93 & 0.47 & 0.88 & 19.63 & 0.00 & -1.12 & -3.58 & Rejected \\
\hline 4 & 1.01 & 0.01 & -0.59 & 0.40 & 0.90 & 3.00 & 0.05 & -0.38 & -1.27 & OK \\
\hline 5 & 1.01 & 0.01 & -0.51 & 0.37 & 0.92 & 0.92 & 0.40 & -0.09 & -0.30 & OK \\
\hline 6 & 1.00 & 0.01 & -1.15 & 0.43 & 0.90 & 22.05 & 0.00 & -1.09 & -3.36 & Rejected \\
\hline 7 & 0.86 & 0.01 & 2.57 & 0.56 & 0.84 & 130.66 & 0.00 & -2.71 & -7.39 & Rejected \\
\hline 8 & 0.89 & 0.01 & 1.67 & 0.62 & 0.84 & 104.95 & 0.00 & -2.74 & -6.87 & Rejected \\
\hline 9 & 0.84 & 0.02 & 2.47 & 0.75 & 0.78 & 191.72 & 0.00 & -4.42 & -10.18 & Rejected \\
\hline 10 & 0.76 & 0.02 & 4.61 & 0.83 & 0.73 & 373.52 & 0.00 & -6.56 & -14.31 & Rejected \\
\hline 11 & 0.69 & 0.02 & 6.95 & 0.84 & 0.70 & 524.86 & 0.00 & -7.72 & -16.39 & Rejected \\
\hline 12 & 0.67 & 0.02 & 7.04 & 0.83 & 0.70 & 674.14 & 0.00 & -8.90 & -18.54 & Rejected \\
\hline 13 & 0.65 & 0.02 & 7.27 & 0.84 & 0.69 & 747.94 & 0.00 & -9.52 & -19.81 & Rejected \\
\hline 14 & 0.66 & 0.02 & 7.08 & 0.83 & 0.69 & 668.35 & 0.00 & -8.96 & -19.12 & Rejected \\
\hline 15 & 0.72 & 0.02 & 5.19 & 0.83 & 0.70 & 466.71 & 0.00 & -7.53 & -16.75 & Rejected \\
\hline 16 & 0.74 & 0.02 & 4.69 & 0.81 & 0.71 & 391.98 & 0.00 & -6.74 & -15.40 & Rejected \\
\hline 17 & 0.77 & 0.02 & 3.46 & 0.79 & 0.74 & 374.17 & 0.00 & -6.49 & -14.87 & Rejected \\
\hline 18 & 0.77 & 0.02 & 3.63 & 0.83 & 0.73 & 350.67 & 0.00 & -6.58 & -14.69 & Rejected \\
\hline 19 & 0.68 & 0.02 & 6.62 & 0.84 & 0.69 & 571.28 & 0.00 & -8.30 & -17.86 & Rejected \\
\hline 20 & 0.64 & 0.02 & 7.46 & 0.88 & 0.65 & 687.76 & 0.00 & -9.63 & -20.38 & Rejected \\
\hline 21 & 0.63 & 0.02 & 7.56 & 0.83 & 0.67 & 742.64 & 0.00 & -9.54 & -20.53 & Rejected \\
\hline 22 & 0.74 & 0.02 & 4.03 & 0.80 & 0.72 & 460.32 & 0.00 & -7.17 & -16.39 & Rejected \\
\hline 23 & 0.73 & 0.02 & 4.20 & 0.82 & 0.70 & 445.52 & 0.00 & -7.23 & -16.77 & Rejected \\
\hline 24 & 0.81 & 0.02 & 2.56 & 0.78 & 0.71 & 215.11 & 0.00 & -4.93 & -12.78 & Rejected \\
\hline
\end{tabular}

1. Wald test is the test that the coefficient for PWXT $=1$ and the constant $=0$.

2. The effect is calculated at the sample mean and given in euro per MWh difference with the sample mean. Bold coefficients and test-statistics are significant at 5\%. 
Table B.6 Estimation results Omel as function of MIX

\begin{tabular}{|c|c|c|c|c|c|c|c|c|c|c|}
\hline & \multicolumn{2}{|c|}{ MIX } & \multicolumn{2}{|c|}{ Constant } & \multicolumn{3}{|c|}{ Wald-test $^{1}$} & \multicolumn{2}{|c|}{ Difference } & \multirow[b]{2}{*}{ Conclusion } \\
\hline & Coeff & St. error & Coeff & St. error & $\mathrm{R}^{2}$ & Wald & Prob & Effect $^{2}$ & $\%$ mean & \\
\hline 1 & 0.93 & 0.02 & 5.28 & 0.74 & 0.84 & 57.46 & 0.00 & 2.30 & 5.03 & Rejected \\
\hline 2 & 0.92 & 0.01 & 5.60 & 0.61 & 0.86 & 81.50 & 0.00 & 2.38 & 5.78 & Rejected \\
\hline 3 & 0.96 & 0.01 & 3.72 & 0.60 & 0.85 & 59.08 & 0.00 & 2.14 & 5.70 & Rejected \\
\hline 4 & 0.94 & 0.02 & 4.60 & 0.63 & 0.82 & 74.69 & 0.00 & 2.55 & 7.16 & Rejected \\
\hline 5 & 0.98 & 0.02 & 3.17 & 0.60 & 0.83 & 63.57 & 0.00 & 2.35 & 6.81 & Rejected \\
\hline 6 & 0.96 & 0.01 & 2.80 & 0.53 & 0.87 & 31.02 & 0.00 & 1.34 & 3.71 & Rejected \\
\hline 7 & 0.93 & 0.01 & 3.22 & 0.49 & 0.91 & 22.26 & 0.00 & 0.50 & 1.23 & Rejected \\
\hline 8 & 0.96 & 0.01 & 3.09 & 0.55 & 0.91 & 28.75 & 0.00 & 1.27 & 2.82 & Rejected \\
\hline 9 & 0.95 & 0.01 & 3.72 & 0.57 & 0.91 & 29.38 & 0.00 & 1.15 & 2.36 & Rejected \\
\hline 10 & 0.93 & 0.01 & 4.84 & 0.63 & 0.90 & 37.58 & 0.00 & 1.29 & 2.47 & Rejected \\
\hline 11 & 0.90 & 0.01 & 7.35 & 0.71 & 0.88 & 72.21 & 0.00 & 2.05 & 3.72 & Rejected \\
\hline 12 & 0.87 & 0.01 & 8.69 & 0.74 & 0.87 & 73.70 & 0.00 & 1.53 & 2.70 & Rejected \\
\hline 13 & 0.87 & 0.01 & 8.63 & 0.69 & 0.89 & 84.37 & 0.00 & 1.50 & 2.64 & Rejected \\
\hline 14 & 0.87 & 0.01 & 8.82 & 0.63 & 0.90 & 109.56 & 0.00 & 1.75 & 3.15 & Rejected \\
\hline 15 & 0.89 & 0.01 & 6.73 & 0.61 & 0.90 & 65.15 & 0.00 & 1.16 & 2.24 & Rejected \\
\hline 16 & 0.91 & 0.01 & 5.90 & 0.57 & 0.91 & 60.18 & 0.00 & 1.20 & 2.40 & Rejected \\
\hline 17 & 0.93 & 0.01 & 5.36 & 0.64 & 0.89 & 56.21 & 0.00 & 1.77 & 3.58 & Rejected \\
\hline 18 & 0.91 & 0.01 & 6.36 & 0.69 & 0.87 & 54.48 & 0.00 & 1.73 & 3.38 & Rejected \\
\hline 19 & 0.88 & 0.01 & 8.56 & 0.81 & 0.84 & 60.60 & 0.00 & 1.82 & 3.34 & Rejected \\
\hline 20 & 0.87 & 0.01 & 9.09 & 0.74 & 0.87 & 76.67 & 0.00 & 1.64 & 2.91 & Rejected \\
\hline 21 & 0.87 & 0.01 & 9.20 & 0.77 & 0.87 & 75.12 & 0.00 & 1.73 & 2.99 & Rejected \\
\hline 22 & 0.82 & 0.01 & 12.63 & 0.70 & 0.88 & 164.36 & 0.00 & 1.83 & 3.10 & Rejected \\
\hline 23 & 0.91 & 0.01 & 6.64 & 0.63 & 0.90 & 65.85 & 0.00 & 1.52 & 2.79 & Rejected \\
\hline 24 & 0.96 & 0.01 & 3.41 & 0.67 & 0.89 & 32.51 & 0.00 & 1.62 & 3.28 & Rejected \\
\hline
\end{tabular}

1. Wald test is the test that the coefficient for PWXT $=1$ and the constant $=0$.

2. The effect is calculated at the sample mean and given in euro per MWh difference with the sample mean. Bold coefficients and test-statistics are significant at 5\%. 
Table B.7 Estimation results POLPX as function of MIX

\begin{tabular}{|c|c|c|c|c|c|c|c|c|c|c|}
\hline & \multicolumn{2}{|c|}{ MIX } & \multicolumn{2}{|c|}{ Constant } & \multicolumn{3}{|c|}{ Wald-test $^{1}$} & \multicolumn{2}{|c|}{ Difference } & \multirow[b]{2}{*}{ Conclusion } \\
\hline & Coeff & St. error & Coeff & St. error & $\mathrm{R}^{2}$ & Wald & Prob & Effect $^{2}$ & $\%$ mean & \\
\hline 1 & 0.93 & 0.02 & 5.28 & 0.73 & 0.78 & 65.76 & 0.00 & 2.55 & 6.83 & Rejected \\
\hline 2 & 1.14 & 0.03 & 7.12 & 0.94 & 0.71 & 707.60 & 0.00 & 11.60 & 35.80 & Rejected \\
\hline 3 & 1.25 & 0.04 & 7.20 & 1.11 & 0.64 & 843.73 & 0.00 & 14.62 & 48.96 & Rejected \\
\hline 4 & 1.90 & 0.07 & -2.44 & 2.16 & 0.49 & 665.37 & 0.00 & 23.01 & 80.97 & Rejected \\
\hline 5 & 2.29 & 0.10 & -7.60 & 2.87 & 0.43 & 603.50 & 0.00 & 27.55 & 100.82 & Rejected \\
\hline 6 & 1.40 & 0.06 & 8.16 & 2.06 & 0.40 & 463.89 & 0.00 & 20.14 & 66.41 & Rejected \\
\hline 7 & 1.10 & 0.04 & 8.02 & 1.77 & 0.46 & 175.86 & 0.00 & 11.69 & 30.89 & Rejected \\
\hline 8 & 0.97 & 0.03 & 8.35 & 1.13 & 0.65 & 155.67 & 0.00 & 6.96 & 17.34 & Rejected \\
\hline 9 & 1.02 & 0.02 & 0.98 & 0.91 & 0.79 & 17.14 & 0.00 & 1.79 & 4.05 & Rejected \\
\hline 10 & 0.99 & 0.02 & 0.46 & 0.79 & 0.85 & 0.31 & 0.74 & -0.08 & -0.17 & $\mathrm{OK}$ \\
\hline 11 & 0.98 & 0.01 & 1.01 & 0.77 & 0.86 & 1.18 & 0.31 & -0.07 & -0.14 & $\mathrm{OK}$ \\
\hline 12 & 0.94 & 0.01 & 2.20 & 0.75 & 0.87 & 15.00 & 0.00 & -0.91 & -1.81 & Rejected \\
\hline 13 & 0.92 & 0.01 & 2.63 & 0.66 & 0.89 & 28.90 & 0.00 & -1.16 & -2.30 & Rejected \\
\hline 14 & 0.91 & 0.01 & 2.53 & 0.64 & 0.89 & 53.81 & 0.00 & -1.82 & -3.64 & Rejected \\
\hline 15 & 0.96 & 0.01 & 1.42 & 0.68 & 0.88 & 9.47 & 0.00 & -0.71 & -1.48 & Rejected \\
\hline 16 & 0.83 & 0.01 & 4.81 & 0.61 & 0.86 & 194.33 & 0.00 & -3.06 & -6.60 & Rejected \\
\hline 17 & 0.66 & 0.02 & 7.83 & 0.87 & 0.66 & 552.53 & 0.00 & -8.31 & -17.68 & Rejected \\
\hline 18 & 0.41 & 0.02 & 16.99 & 0.89 & 0.46 & $1,181.79$ & 0.00 & -12.10 & -24.59 & Rejected \\
\hline 19 & 0.19 & 0.01 & 18.73 & 0.60 & 0.30 & $7,014.51$ & 0.00 & -22.70 & -44.53 & Rejected \\
\hline 20 & 0.11 & 0.01 & 20.23 & 0.49 & 0.20 & \#\#\#\#\#\# & 0.00 & -28.93 & -52.56 & Rejected \\
\hline 21 & 0.17 & 0.01 & 18.06 & 0.58 & 0.27 & $8,978.20$ & 0.00 & -25.55 & -48.89 & Rejected \\
\hline 22 & 0.34 & 0.01 & 11.67 & 0.63 & 0.49 & 4,933.02 & 0.00 & -18.26 & -40.03 & Rejected \\
\hline 23 & 0.46 & 0.01 & 9.37 & 0.65 & 0.61 & $3,243.59$ & 0.00 & -15.08 & -33.46 & Rejected \\
\hline 24 & 0.67 & 0.02 & 7.81 & 0.65 & 0.73 & 557.08 & 0.00 & -5.53 & -13.64 & Rejected \\
\hline
\end{tabular}

1. Wald test is the test that the coefficient for PWXT $=1$ and the constant $=0$.

2. The effect is calculated at the sample mean and given in euro per MWh difference with the sample mean. Bold coefficients and test-statistics are significant at 5\%. 
Table B.8 Estimation results PWXT as function of MIX

\begin{tabular}{|c|c|c|c|c|c|c|c|c|c|c|}
\hline & \multicolumn{2}{|c|}{ MIX } & \multicolumn{2}{|c|}{ Constant } & \multicolumn{3}{|c|}{ Wald-test $^{1}$} & \multicolumn{2}{|c|}{ Difference } & \multirow[b]{2}{*}{ Conclusion } \\
\hline & Coeff & St. error & Coeff & St. error & $\mathrm{R}^{2}$ & Wald & Prob & Effect $^{2}$ & $\%$ mean & \\
\hline 1 & 1.01 & 0.00 & -0.31 & 0.16 & 0.99 & 1.96 & 0.14 & -0.06 & -0.16 & $\mathrm{OK}$ \\
\hline 2 & 1.00 & 0.00 & -0.08 & 0.13 & 0.99 & 1.02 & 0.36 & 0.05 & 0.13 & $\mathrm{OK}$ \\
\hline 3 & 1.01 & 0.00 & -0.12 & 0.15 & 0.99 & 4.43 & 0.01 & 0.14 & 0.45 & Rejected \\
\hline 4 & 1.00 & 0.00 & -0.12 & 0.08 & 1.00 & 1.20 & 0.30 & -0.03 & -0.13 & $\mathrm{OK}$ \\
\hline 5 & 1.00 & 0.00 & -0.14 & 0.12 & 0.99 & 5.94 & 0.00 & -0.21 & -0.86 & Rejected \\
\hline 6 & 1.00 & 0.00 & -0.06 & 0.11 & 0.99 & 0.74 & 0.48 & -0.06 & -0.20 & $\mathrm{OK}$ \\
\hline 7 & 1.00 & 0.00 & -0.20 & 0.14 & 0.99 & 3.06 & 0.05 & -0.18 & -0.46 & Rejected \\
\hline 8 & 1.00 & 0.00 & -0.33 & 0.21 & 0.99 & 2.05 & 0.13 & -0.20 & -0.36 & $\mathrm{OK}$ \\
\hline 9 & 1.00 & 0.00 & -0.10 & 0.13 & 1.00 & 1.50 & 0.22 & -0.11 & -0.18 & $\mathrm{OK}$ \\
\hline 10 & 1.00 & 0.00 & -0.07 & 0.14 & 1.00 & 1.12 & 0.33 & -0.11 & -0.16 & $\mathrm{OK}$ \\
\hline 11 & 1.00 & 0.00 & -0.02 & 0.14 & 1.00 & 0.46 & 0.63 & -0.06 & -0.09 & $\mathrm{OK}$ \\
\hline 12 & 1.00 & 0.00 & 0.25 & 0.17 & 1.00 & 1.93 & 0.15 & -0.04 & -0.05 & $\mathrm{OK}$ \\
\hline 13 & 1.00 & 0.00 & 0.15 & 0.12 & 1.00 & 1.39 & 0.25 & -0.02 & -0.03 & $\mathrm{OK}$ \\
\hline 14 & 1.00 & 0.00 & 0.21 & 0.12 & 1.00 & 1.52 & 0.22 & 0.03 & 0.05 & $\mathrm{OK}$ \\
\hline 15 & 1.00 & 0.00 & 0.16 & 0.13 & 1.00 & 0.83 & 0.43 & 0.03 & 0.04 & $\mathrm{OK}$ \\
\hline 16 & 1.00 & 0.00 & 0.05 & 0.11 & 1.00 & 1.69 & 0.19 & -0.07 & -0.11 & $\mathrm{OK}$ \\
\hline 17 & 1.00 & 0.00 & 0.04 & 0.14 & 1.00 & 0.08 & 0.92 & -0.01 & -0.01 & $\mathrm{OK}$ \\
\hline 18 & 1.00 & 0.00 & -0.17 & 0.15 & 1.00 & 0.79 & 0.46 & -0.11 & -0.17 & $\mathrm{OK}$ \\
\hline 19 & 1.00 & 0.00 & -0.05 & 0.11 & 1.00 & 0.67 & 0.51 & -0.09 & -0.12 & $\mathrm{OK}$ \\
\hline 20 & 1.00 & 0.00 & 0.13 & 0.08 & 1.00 & 1.28 & 0.28 & 0.05 & 0.08 & $\mathrm{OK}$ \\
\hline 21 & 1.00 & 0.00 & 0.00 & 0.05 & 1.00 & 0.03 & 0.97 & -0.01 & -0.01 & $\mathrm{OK}$ \\
\hline 22 & 1.00 & 0.00 & 0.05 & 0.16 & 1.00 & 0.77 & 0.46 & 0.08 & 0.15 & $\mathrm{OK}$ \\
\hline 23 & 1.01 & 0.00 & -0.23 & 0.15 & 1.00 & 2.86 & 0.06 & 0.06 & 0.12 & $\mathrm{OK}$ \\
\hline 24 & 1.00 & 0.00 & -0.10 & 0.15 & 0.99 & 1.49 & 0.23 & 0.07 & 0.15 & $\mathrm{OK}$ \\
\hline
\end{tabular}

1. Wald test is the test that the coefficient for PWXT $=1$ and the constant $=0$.

2. The effect is calculated at the sample mean and given in euro per MWh difference with the sample mean. Bold coefficients and test-statistics are significant at 5\%. 